\title{
A Review of Proton Conductivity in Cellulosic Materials
}

\author{
Olena Selyanchyn ${ }^{1}$, Roman Selyanchyn ${ }^{2}$ and Stephen M. Lyth ${ }^{1,2,3 *}$ \\ ${ }^{1}$ Department of Automotive Science, Graduate School of Integrated Frontier Sciences, Kyushu University, Fukuoka, Japan, \\ ${ }^{2}$ International Institute for Carbon-Neutral Energy Research (WPI-I2CNER), Kyushu University, Fukuoka, Japan, ${ }^{3}$ Platform for \\ Inter/Transdisciplinary Energy Research (Q-PIT), Kyushu University, Fukuoka, Japan
}

OPEN ACCESS

Edited by:

Su Yun Ha,

Washington State University,

United States

Reviewed by:

Signe Kjelstrup,

YIldiz Technical University, Norwegian

University of Science and

Technology, Norway

Filipe M. Figueiredo,

University of Aveiro, Portugal

*Correspondence:

Stephen M. Lyth

Iyth@i2cner.kyushu-u.ac.jp

Specialty section:

This article was submitted to Fuel Cells, a section of the journal

Frontiers in Energy Research

Received: 18 August 2020

Accepted: 23 October 2020

Published: 24 November 2020

Citation:

Selyanchyn O, Selyanchyn $R$ and Lyth SM (2020) A Review of Proton

Conductivity in Cellulosic Materials.

Front. Energy Res. 8:596164.

doi: 10.3389/fenrg.2020.596164
Cellulose is derived from biomass and is useful in a wide range of applications across society, most notably in paper and cardboard. Nanocellulose is a relatively newly discovered variant of cellulose with much smaller fibril size, leading to unique properties such as high mechanical strength. Meanwhile, electrochemical energy conversion in fuel cells will be a key technology in the development of the hydrogen economy, but new lower cost proton exchange membrane (PEM) materials are needed. Nanocellulose has emerged as a potential candidate for this important application. In this review we summarize scientific developments in the area of cellulosic materials with special emphasis on the proton conductivity, which is the most important parameter for application in PEMs. We cover conventional cellulose and nanostructured cellulose materials, polymer composites or blends, and chemically modified cellulose. These developments are critically reviewed, and we identify interesting trends in the literature data. Finally, we speculate on future directions for this field.

Keywords: nanocellulose, cellulose nanofibers, cellulose nanocrystals, proton exchange membrane, proton conductivity, fuel cell, composite membrane

\section{INTRODUCTION}

Cellulose is a natural polysaccharide contained in biomass and is the most abundant biopolymer on the planet. The global annual amount of cellulose produced by the biosphere is estimated to be more than $1.5 \times 10^{15} \mathrm{~kg}$, representing a huge material resource comparable with the global reserves of fossil fuels and minerals (Klemm et al., 2005; Heinze, 2016). In the era of accelerating climate change, polysaccharides and cellulose in particular, are increasingly being considered as useful material feedstocks for a variety of purposes. (Mohanty et al., 2018). This is due to their abundance, natural renewability, established processing technologies, and a centuries-long record of utilization. General applications of cellulose and its derivatives include the paper and packaging industry, plastics and building materials production, filtration membranes, food additives, and biofuels production (Thomas et al., 2018).

Structurally, cellulose is a fiber-like element contained in plant cell walls (Figure 1A). Cellulose is a rather simple linear polymer (Figure 1B) comprised of glucose units bound together via 1,4 betaglycosidic bonds, common in a wide variety of plants and microorganisms. Due to presence of reactive hydroxyl groups in its chemical structure, the long polymer chains of cellulose bind together via plurality of intra- and intermolecular hydrogen bonds, forming microfibrils (Gibson, 2012). Meanwhile, cellulose coexists with related structures. Hemicelluloses are a family of polysaccharide polymers having more complex heterostructures (Figure 1C), while lignin is a random highly branched amorphous polymer with aromatic polyphenol units in its structure (Figure 1D). Both components varying in different types of vascular plants (Heitner et al., 2010; Irmak, 2018). In different wood species, the relative composition if these three materials varies significantly: with 

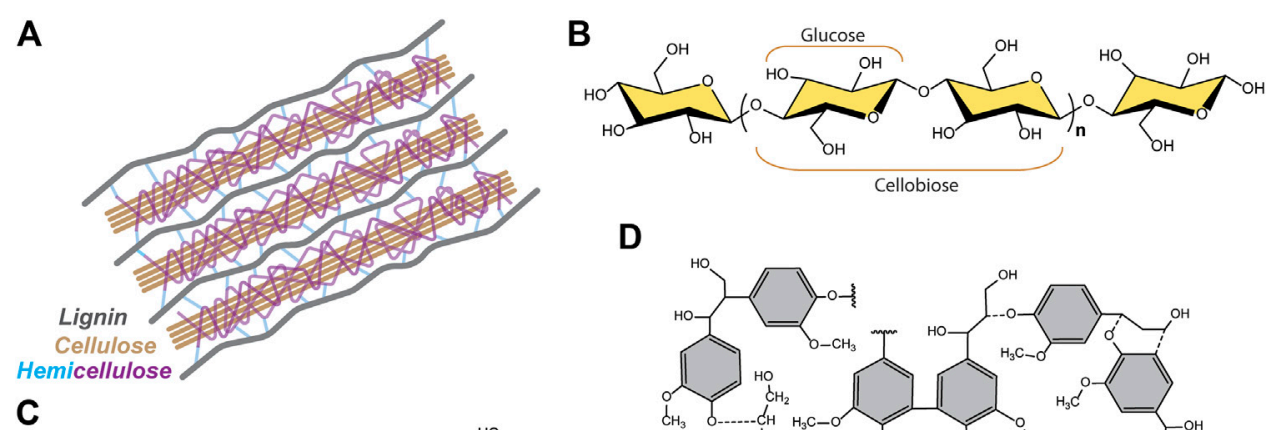

\section{D}
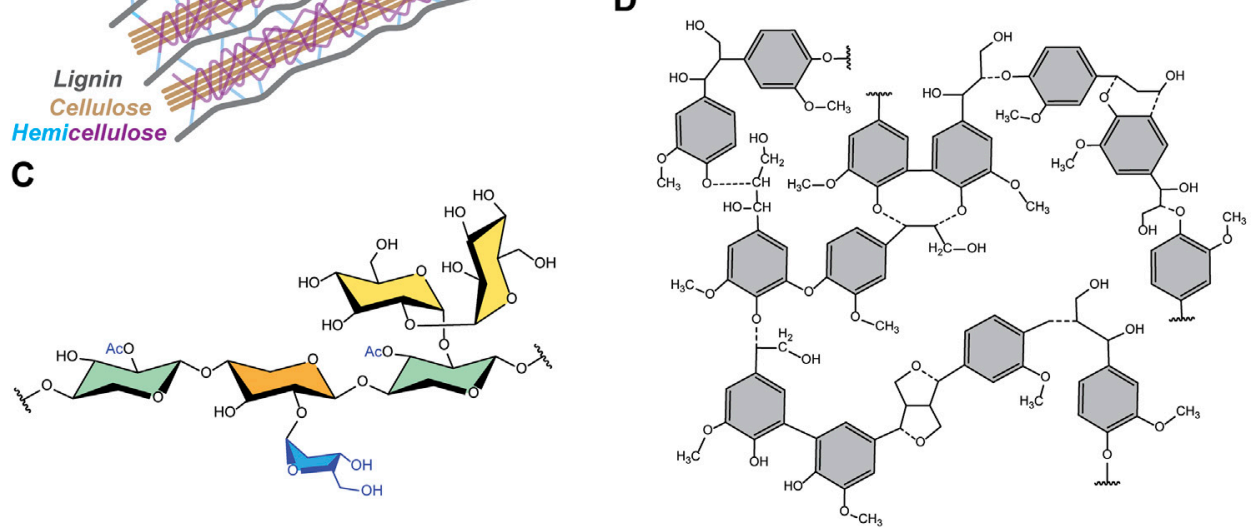

FIGURE 1 | (A) Hierarchical structure of the plant cell wall and chemical structures of its main components: (B) cellulose, (C) hemicellulose and (D) lignin. Adapted from (Heitner et al., 2010; Irmak, 2018).

cellulose generally comprising $\sim 40$ to $45 \mathrm{wt} . \%$, lignin 22 to $31 \mathrm{wt} . \%$, and hemicellulose $\sim 19$ to $32 \mathrm{wt} \%$ of the dry material (Sjöström, 1993). Cellulose is usually separated from hemicellulose and lignin before use in applications.

Recently considerable research interest has been focused on the nanostructured forms of cellulose, often referred to collectively as nanocellulose. Nanocellulose can be produced by microorganisms (e.g. algae or bacteria); obtained from animal sources (e.g. tunicates); or extracted from higher plants by disassembling and sorting of hierarchical structure components formed in nature (Eichorn et al., 2010). In bacteria, unlike plants, nanocellulose is produced in its pure form, free of other polymers, and is referred as bacterial cellulose (BC). When using higher plants, microfibers of cellulose are separated from the lignin and hemicelluloses and then mechanically defibrillated to produce cellulose nanofibers (CNFs) several micrometers in length, with diameters of $\sim 2-20 \mathrm{~nm}$. Alternatively, controlled hydrolysis of cellulose by strong acids is used to produce smaller cellulose nanocrystals (CNCs) e.g. $70-300 \mathrm{~nm}$ in length and 2-70 $\mathrm{nm}$ in diameter (Eichorn et al., 2010; Habibi et al., 2010), but can also change the chemical structure. Defibrillation of cellulose was first discovered by Turbak et al., in 1977 when they processed wood pulp fibers in a high-pressure homogenizer (Turbak et al., 1983). The methods of production today also include a number of mechanical approaches (e.g. grinding or shear mixing). The source of nanostructured cellulose and the manufacturing processes both define the microstructure of the final material, which can vary significantly at the microscale (Figure 2). For example, CNFs tend to be more amorphous, whilst CNCs have a higher degree of crystallinity.

The extraordinary mechanical properties of nanocellulose are one of the most attractive features. Impressively, the elastic modulus of a single fibril is reported to be as high as $50 \mathrm{GPa}$ in the transverse direction, and up to $18.4 \mathrm{GPa}$ in the longitudinal direction (Usov et al., 2015). Other important features of celluloses are relatively low density $\left(1.5-2.6 \mathrm{~g} / \mathrm{cm}^{3}\right)$ compared to other reinforcement materials (Dufresne, 2013; Jonoobi, et al., 2015), and its possession of a reactive surface allowing for a wide variety of chemical modifications (Thomas et al., 2018). Cellulose is non-toxic, biodegradable and a natural renewable resource, which are also important factors from the point of view of sustainability.

Because of its unique structural features and physical properties, nanocellulose is viewed as a potentially useful biopolymer and is actively studied in a wide variety of applications. The incorporation of nanocellulose in composite materials is expected to provide mechanical reinforcement, advanced coatings, sensors, food additives, supercapacitors and batteries, gas separation membranes, medical devices and bioplastics (Guilminot et al., 2007; Hou et al., 2015; Yamasaki et al., 2019; Trache et al., 2020; Dias et al., 2020). Nanocellulose has been enthusiastically embraced in the automotive industry, most clearly demonstrated by the Nanocellulose Vehicle Project in Japan ${ }^{1}$. This academic-industry-government collaboration aims to increase vehicle efficiency by lowering the weight without compromising structural integrity, via the inclusion of CNF composites. A prototype vehicle based on this concept was demonstrated at the Tokyo Motor Show in November $2019^{2}$.

${ }^{1}$ Nanocellulose Vehicle Project http://www.rish.kyoto-u.ac.jp/ncv/uploads/en.pdf (2019).

${ }^{2}$ https://www.carscoops.com/2019/10/nano-cellulose-vehicle-concept-is-themost-eco-friendly-supercar-ever/ 


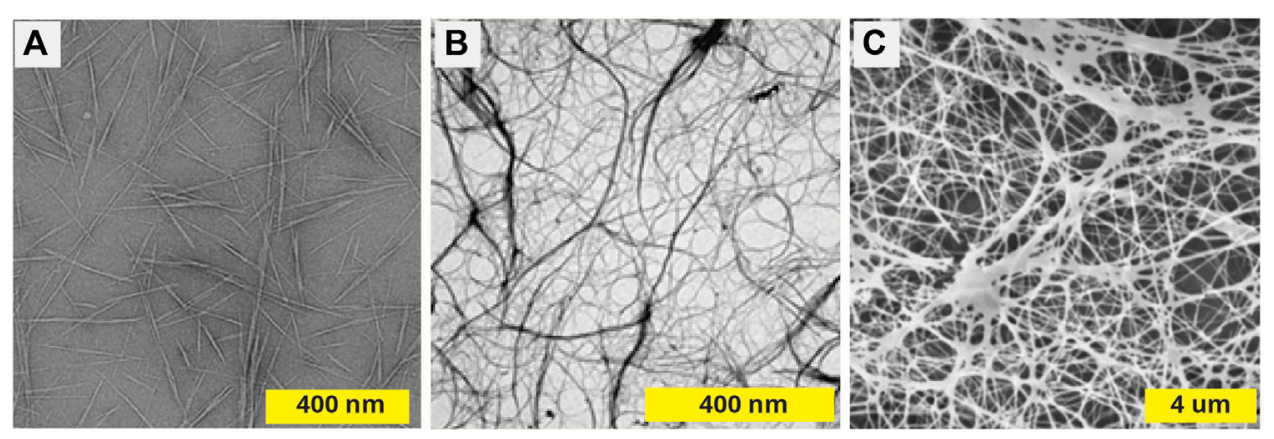

FIGURE 2 | Electron microscopy of dried nanocelluloses prepared from different sources: (A) TEM image of cellulose nanowhiskers obtained from sisal (Reprinted with permission from (Garcia de Rodriguez, et al., 2006). Copyright 2006 Springer) (B) TEM image of cellulose nanofibers obtained from banana peels by high-pressure homogenizer (Reprinted with permission from (Pelissari et al., 2014). Copyright 2014 Springer). (C) SEM of bacterial nanocellulose produced by Gluconacetobacter xylinus (Reproduced with permission from (Ataide et al., 2017).

Fuel cells are electrochemical devices which can transform chemical energy into electrical energy with high efficiency. Polymer electrolyte membrane fuel cells (PEMFCs) are one of the most common varieties of fuel cell (schematically shown in Figure 3). The core component of a PEMFC is the proton exchange membrane (PEM). This allows the diffusion of protons (i.e. hydrogen ions) through its bulk and provides mechanical support for the electrodes, whilst also acting as a selective barrier to fuel and electrons. Hydrogen fuel is oxidized over a platinum catalyst at the anode, splitting into protons and electrons. Meanwhile, oxygen is reduced over a platinum catalyst at the cathode, combining with protons and electrons to form water. The potential different between these two half reactions generates a voltage, which drives the diffusion of hydrogen ions through the PEM, as well as the movement of electrons around the external circuit, generating electricity. Direct methanol fuel cells (DMFCs) operate by a similar concept but utilize methanol as a fuel rather than hydrogen.

Currently, Nafion® (Du Pont) is the benchmark PEM material for fuel cells, along with other related sulfonated perfluoropolymers that have been recently developed, such as Aquivion (Breitwieser et al., 2017). The characteristic chemical structure of Nafion (Figure 4A) contains a hydrophobic fluorinated backbone, with hydrophilic acidic side chains. The polymeric backbone is similar in structure to polytetrafluoroethylene (PTFE), providing thermal, chemical and mechanical stability (Allen et al., 2015). Meanwhile, due to the highly electronegative fluorine atoms in the side chain, the sulfonic acid group has a very high pKa value of -6.0 (Mauritz and Moore, 2004). As such, sulfonated perfluoropolymers are often referred as solid superacids. The combination of hydrophilic and hydrophobic regions is reported to create a phase separated nanostructure with percolating ion conducting channels specifically advantageous for efficient proton transport (Kreuer, 2001). This unique chemical structure and morphology gives origin to high proton conductivity in a fully hydrated state $\left(>0.1 \mathrm{~S} \mathrm{~cm}^{-1}\right)$. In the majority of PEMs, proton transport is strongly dependent on water content and is posited to occur through water-swollen hydrophilic channels formed around the acidic moieties (Peckham and Holdcroft, 2010). The various mechanisms of proton transport include the Grotthuss mechanism (i.e. structural diffusion of protons resulting in charge exchange between water molecules), the vehicular mechanism (i.e. physical diffusion of protons in the form of aqueous cations via electroosmotic flow e.g. $\mathrm{H}_{3} \mathrm{O}^{+}$, $\mathrm{H}_{5} \mathrm{O}_{2}{ }^{+}, \mathrm{H}_{9} \mathrm{O}_{4}{ }^{+}$, etc.) (Kreuer et al., 2004), and surface transport (i.e. proton hopping along the functional moieties of the active material). These mechanisms are usually intermixed (Peckham and Holdcroft, 2010). In highly hydrated systems as is commonly the case for hydrogen fuel cells, the vehicular and Grotthuss transport mechanisms predominate and are usually characterized by measurement of lower activation energies compared to surface transport.

A major issue with Nafion and other sulfonated perfluoropolymers is their high cost (e.g. 600 to 1200 US\$ m2) which is particularly important for the wide spread uptake of fuel cell electric vehicles (FCEVs) and portable electrical devices (Jiang et al., 2015). Another disadvantage is the limited operation temperature driven by necessity of membrane humidification for proton conduction (Kreuer, 2001). In addition, the gas permeability of Nafion is relatively high, which prevents the use of thinner membranes due to fuel crossover (Bayer et al., 2016). As such, the synthesis of alternative materials for PEMs with similar polymer architectures is under investigation, i.e. combining proton conducting acid-bearing functionalities with hydrocarbon polymer backbones. These include materials such as sulfonated poly(ether ether ketone) (SPEEK, Figure 4B); sulfonated poly(aryl ether sulfones) (SPAES); and sulfonated polyimides (SPI) (Peckham and Holdcroft, 2010; Feng et al., 2018). In addition, more exotic nanomaterials such as graphene, or graphene oxide have been investigated for use in PEMs (Cao et al., 2011; Xu et al., 2011; Bayer et al., 2014; Bayer et al., 2016; Bayer et al., 2017). However, none of the above materials significantly impact the issue of cost.

Necessary requirements for new PEM materials include high ionic conductivity, low gas permeability, high mechanical stability, chemical resistance in strong oxidizing and reducing environments, and the ability to fabricate membranes without 


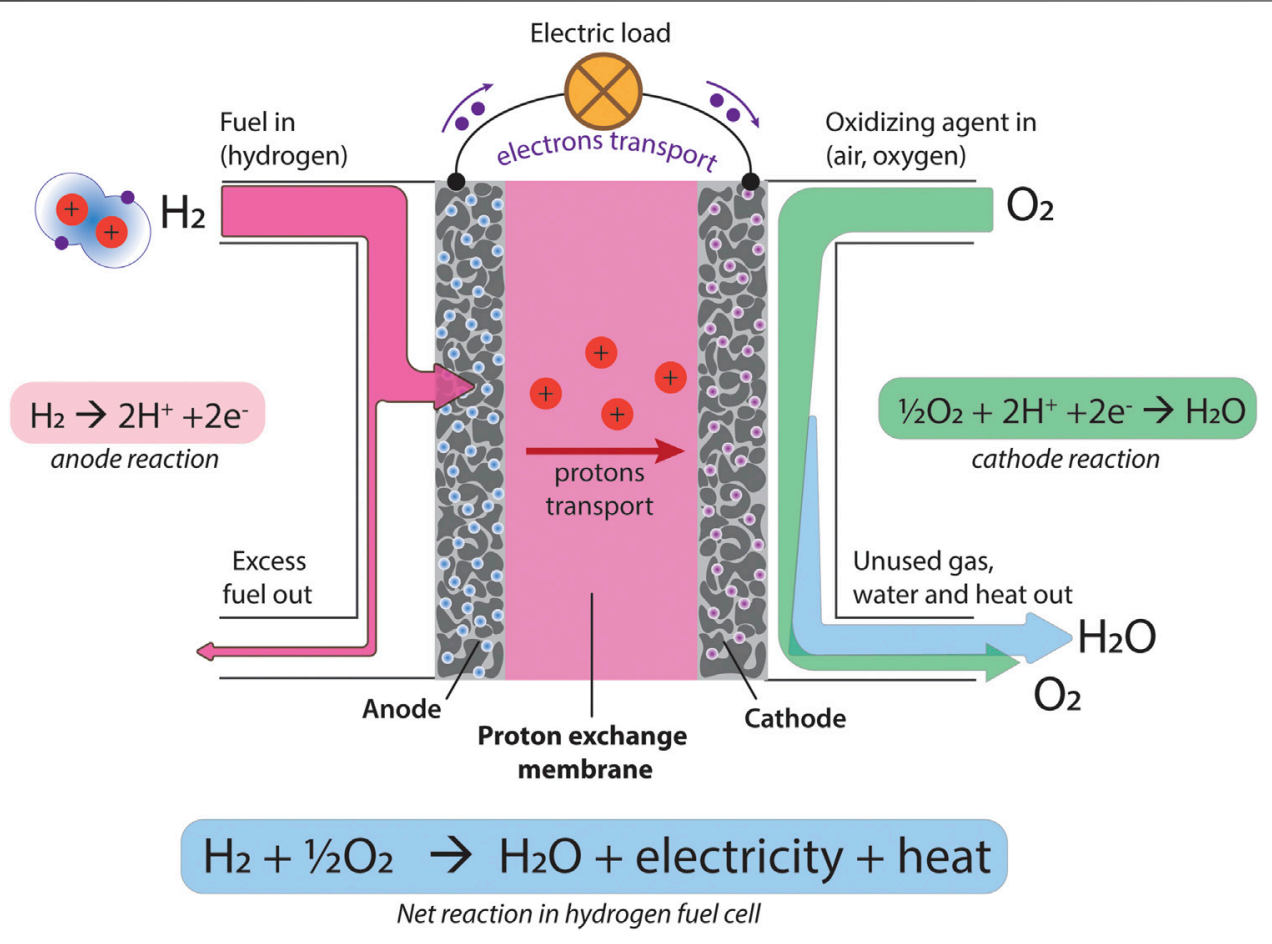

FIGURE 3 | Schematic representation of a hydrogen fuel cell, proton transport through the membrane, and the chemical reactions taking place at the anode (hydrogen oxidation reaction) and cathode (oxygen reduction reaction).

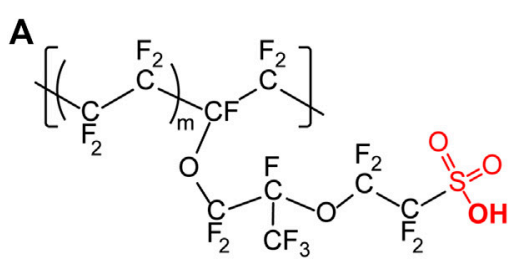<smiles>[B]c1ccc(C(=O)c2ccc(C(=O)c3ccc(Oc4ccc5c(c4)OCO5)cc3)cc2)cc1</smiles>

FIGURE 4 | Chemical structure of Nafion (EW 1100), $\mathrm{m}=6.5$ (Mauritz and Moore, 2004) and sulfonated polyetherketone (SPEEK) (Klemm et al., 2005).

pinholes. Moreover, considering PEMFC architecture, the membrane should be stable under compression in a stack at temperatures up to $120^{\circ} \mathrm{C}$, under highly variable humidity conditions (Gardner and Anantaraman 1998). Cellulosic materials fulfill many of the requirements expected of PEMs, and an increasing number of research groups are working in this field (Vilela et al., 2019). Several tens of studies on this topic have been published thus far, and we expect that this number will rapidly increase as the potential of these interesting materials in fuel cell membranes is recognized.

Several recent review papers have been devoted to the application of cellulose and nanocellulose in PEMs, anionexchange membranes, electrocatalyst supports (Vilela et al., 2019), and their broader application in electronic devices (Dias et al., 2020; Trache et al., 2020). Meanwhile, in this review article we focus more specifically on proton conduction in cellulosebased materials, and their application in PEMs and hydrogen fuel cells. We directly and quantitively compare different results in the literature to identify global trends across the wide range of cellulosic materials studied to date. The studies are grouped into four main areas: 1) pure cellulose; 2) polymer/cellulose blends; 3) chemically modified cellulose; 4) cellulose blends with small molecules (e.g. ionic liquids or aromatic heterocycle compounds) (Figure 5). Based on these trends, we discuss the advantages and disadvantages of cellulose-based PEMs. Finally, we propose promising directions for future research.

\section{METHODOLOGY AND POINTS OF NOTE}

Discussion and comparison of the ionic conductivity of different ionomer materials should be always performed with caution. Results may be presented in different units, plotted using different methodology, or measured in completely different experimental architectures. For convenient comparison between the different studies and with benchmark materials like Nafion, we have here 


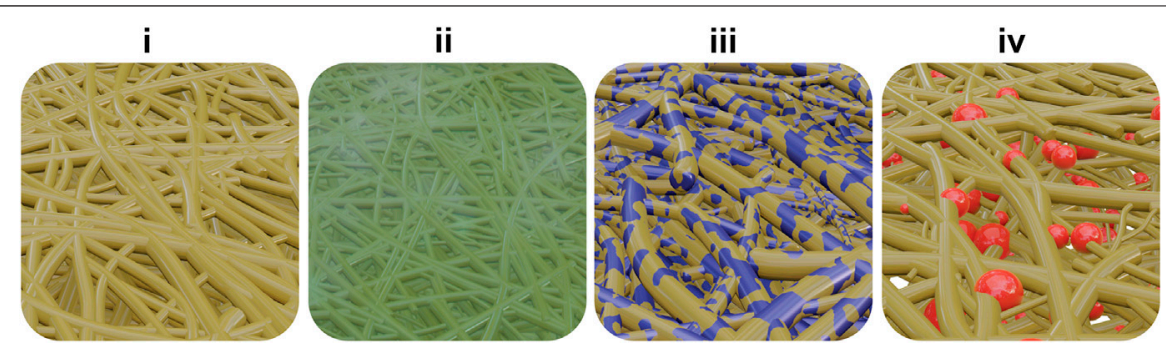

FIGURE 5 | Schematic representation of the main variations of cellulose PEMs at the focus of this study: 1) pristine nanocellulose; 2) polymer blends; 3) chemically modified cellulose; 4) blends with small molecules.

standardized the units of conductivity to $\mathrm{mS} \cdot \mathrm{cm}^{-1}$, and adapted graphs from the original studies to natural logarithms, i.e. $\ln (\sigma$, $\left.\mathrm{S} \cdot \mathrm{cm}^{-1}\right)$. Activation energy data was re-calculated from published data, and the units standardized to $\mathrm{kJ} \cdot \mathrm{mol}^{-1}$ (whilst units of $\mathrm{eV}$ are also included where appropriate).

Another consideration is that the ionic conductivity $(\sigma)$ can be measured either in in-plane $\left(\sigma_{\|}\right)$, or through-plane $\left(\sigma_{\perp}\right)$ configurations. Especially for PEM applications, the throughplane orientation is more relevant, because hydrogen ions diffuse between electrodes through the bulk of the membrane. However, many reports only perform in-plane conductivity measurements, or worse, do not specify which configuration was used. The difference in values between the in-plane and through-plane conductivities are actually rather significant. For example, in extruded blends of Nafion, the ratio of $\sigma_{\|}: \sigma_{\perp}$ is around 3.6 (Gardner and Anantaraman, 1998). This effect is even more pronounced for layered materials like graphene oxide, where $\sigma_{\|}: \sigma_{\perp} \approx 170$ (Bayer et al., 2017). Nanocellulose fibers also have anisotropic geometry, and may therefore be expected to have high $\sigma_{\|}: \sigma_{\perp}$ ratios. This has indeed been observed in polymer composites with bacterial cellulose (Gadim et al., 2017) where $\sigma_{\|}: \sigma_{\perp}$ was $>4$ at room temperatures and low humidity. Therefore, this matter should be carefully considered.

Another point of note is that other biomass-derived carbohydrates such as chitosan can also be used in PEM applications, however at present better proton conductivity is still required (Ma and Sahai, 2013). Another drawback of chitosan is its solubility in the dilute acidic environment of PEMFCs, while nanocellulose more tolerant to such conditions (Vilela et al., 2019). As such, chitosan-based materials are not considered in this review.

\section{CELLULOSE-BASED PEMS}

\section{Pristine Cellulosic Materials}

Fundamental investigations into the electrical conductivity of natural polysaccharides were first reported by Murphy in the 1960 s, specifically on natural cellulose (i.e. cotton) in both dry (Murphy, 1960a, 1960b), and humid conditions (Murphy, 1960a, 1960b). The conductivity of bulk compressed samples was measured, and the significant influence of even trace amounts of absorbed water was realized. Dry cellulose was reported to have very low conductivity in the range from $10^{-16}$ to $10^{-9} \mathrm{mS} \cdot \mathrm{cm}^{-1}$ between 25 and $180^{\circ} \mathrm{C}$, respectively. Meanwhile, at $100 \% \mathrm{RH}$, the conductivity increased by up to 12 orders of magnitude (Murphy, 1960a, 1960b). It is not entirely clear from their description if these measurements were performed in- or through-plane. To explain this strong dependence on water content, theoretical models were built and it was assumed that cellulose possesses periodically distributed “ion-generating sites" where lower energy is required for water dissociation to $\mathrm{H}_{3} \mathrm{O}^{+}$and $\mathrm{OH}^{-}$, increasing the conductivity. It wasn't until 1963 that it was suggested that ionic rather than electronic conduction was responsible for the observed results, after the products of electrolysis were detected during measurements (Murphy, 1960a, 1960b). It was postulated that "conduction in dry cellulose involves tunneling of the proton between equivalent sites, the one in the ion, the other in an adjacent neutral molecule" (Murphy, 1960a, 1960b). Following studies investigated the ionic conductivity of cellulose derivatives, e.g. cellulose acetate, showing that the conductivity decreases by $\sim 1$ order of magnitude in dry samples doped with various ion salts (e.g. LiCl) (Barker et al., 1964a, 1964b).

Over a decade after this cluster of early studies, Crofton and Patrick studied the conductivity of cellulose, cellulose acetate, and ethyl cellulose with various water contents, experimentally verifying the hopping conduction mechanism at elevated temperature (Crofton and Patrick, 1981). In another study, the conductivity was reported to increase faster at higher temperature $\left(>150^{\circ} \mathrm{C}\right)$ in wood-derived cellulose (Betula tauschii, or Japanese white birch), attributed to a second order phase transition after which the breaking of hydrogen bonds results in increased thermal motion (Takahashi and Takenaka, 1983).

Another two decades later, Evans et al., fabricated $50 \mu \mathrm{m}$ thick PEMs from bacterial cellulose (Evans et al., 2003). Separately, bacterial cellulose membranes of the same thickness were decorated with palladium via incubation in hexachloropalladate solution. These palladium-decorated cellulose electrodes were attached to the cellulose PEM and self-adhered upon drying. This unconventional cellulose membrane electrode assembly (MEA) was used as a proto-fuel cell, generating a power density of $84.3 \times 10^{-3} \mathrm{~mW} \cdot \mathrm{cm}^{-2}$ when $\mathrm{H}_{2}$ was supplied to the anode. The $\mathrm{H}_{2}$ permeability was reported to be 1.75 times lower compared to Nafion 117. To the best of our knowledge, this was the first fuel cell fabricated from a cellulose PEM and was an important proof-of-concept. The low power 
density may be attributed to several factors. One reason may be the use of bacterial cellulose as the catalyst support, resulting in low electronic conductivity and unoptimized porosity compared to conventional carbon black electrocatalyst supports. In addition, the use of palladium rather than a conventional platinum electrocatalyst may have significantly limited the performance. Finally, the low proton conductivity of unmodified cellulose also likely contributed to the poor performance, but unfortunately no conductivity values were reported.

Over a decade later, Bayer et al. performed a comprehensive study on the ionic conductivity of nanocellulose membranes, and their application in PEMFCs (Bayer et al., 2016). In this work, we used aqueous dispersions of CNF (provided by the University of Maine) to fabricate membranes with a thickness of $30 \mu \mathrm{m}$ by vacuum filtration. CNCs were also investigated, but the results are classed as acid modification, and are discussed in a later section. Detailed through-plane proton conductivity measurements were performed on CNF membranes by systematically varying the temperature and relative humidity $(\mathrm{RH})$. The highest conductivity was measured to be $0.05 \mathrm{mS} \cdot \mathrm{cm}^{-1}$ at $100^{\circ} \mathrm{C}$ and $100 \% \mathrm{RH}$, attributed to a Grotthuss-like water-mediated proton conduction mechanism with an activation energy of $20.4 \mathrm{~kJ} \cdot \mathrm{mol}^{-1}(0.21 \mathrm{eV})$ (Figure 6). Importantly for PEMFC applications, the hydrogen gas permeability was three orders of magnitude lower than Nafion. A PEMFC assembled using a CNF PEM achieved a power density of $0.79 \mathrm{~mW} \cdot \mathrm{cm}^{-2}$. Although an order of magnitude higher than the value reported by Evans et al., this number is still rather low. These experiments were performed in a conventional PEMFC configuration, and therefore the low power density is simply attributed to the low conductivity of unmodified CNF membranes.

Soon later, a detailed study of anhydrous proton conduction in different types of nanocellulose was performed by Jankowska et al. (Figure 7) (Jankowska et al., 2018). They investigated the relationship between microstructure and proton conductivity at temperature range from 60 to $210^{\circ} \mathrm{C}$. Microcrystalline and microfiber based cellulose membranes with larger feature sizes were found to have relatively low conductivity $(2.5 \times$ $10^{-10} \mathrm{mS} \cdot \mathrm{cm}^{-1}$ and $4.7 \times 10^{-9} \mathrm{mS} \cdot \mathrm{cm}^{-1}$, respectively, at $\left.100^{\circ} \mathrm{C}\right)$. More nanostructured varieties of cellulose such as CNC and CNF had higher conductivities $\left(3.7 \times 10^{-8} \mathrm{mS} \cdot \mathrm{cm}^{-1}\right.$ and $1.2 \times$ $10^{-7} \mathrm{mS} \cdot \mathrm{cm}^{-1}$, respectively). Meanwhile, a pelletized $\mathrm{CNC}$ powder with the smallest feature size had the highest conductivity $\left(8.2 \times 10^{-7} \mathrm{mS} \cdot \mathrm{cm}^{-1}\right)$. This work suggests that proton conduction in anhydrous conditions is surface mediated, with the surface to volume ratio playing an important role. As such the microstructure and textural properties should be carefully considered for PEM applications. Due to the anhydrous measurement conditions, the reported conductivities are much lower than those reported above in humidified conditions.

Overall, investigation of the proton conductivity of pure cellulosic materials is of fundamental interest in terms of elucidating conduction mechanisms, the effect of microstructure, and providing baselines for future study. However, the reported conductivities are consistently too low

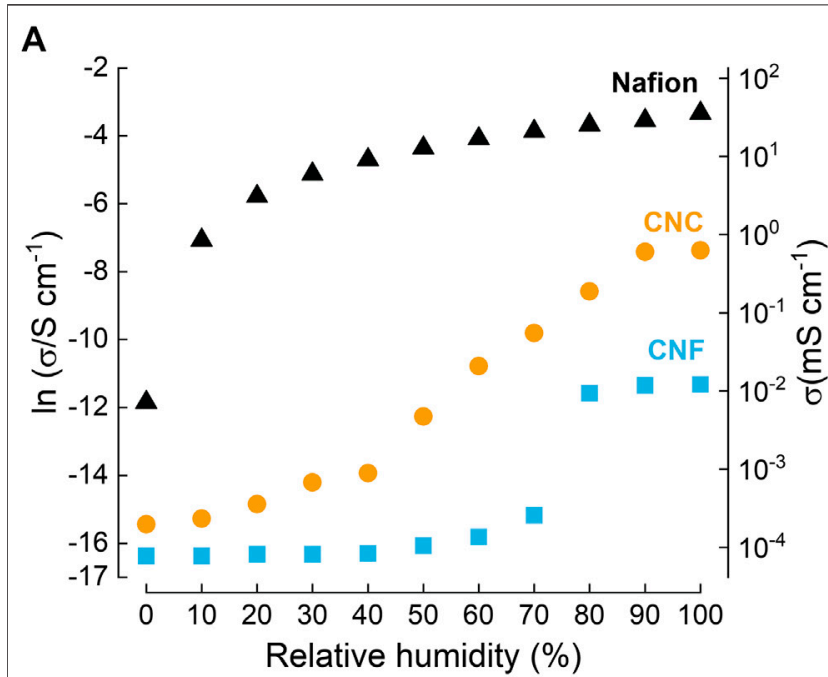

B

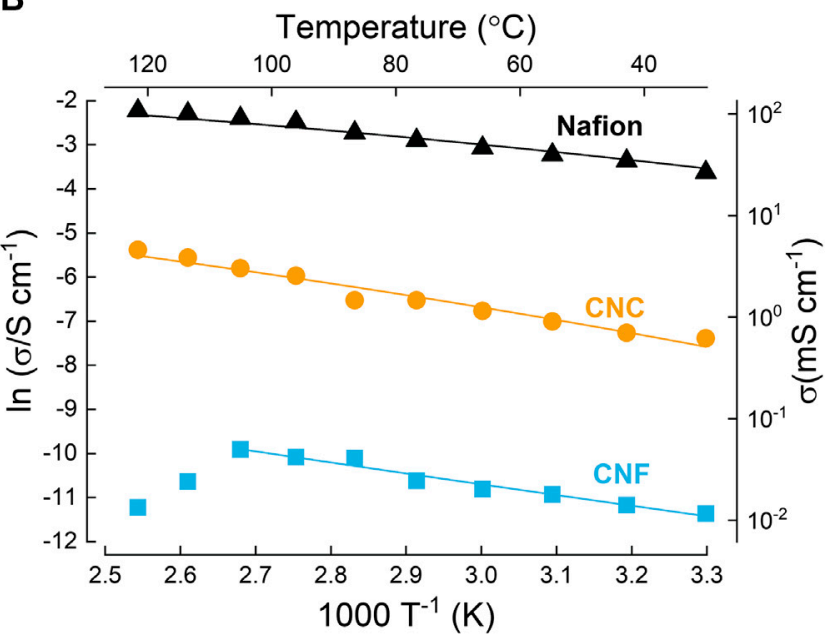

FIGURE 6 | Proton conductivity in nanocellulose. (A) Dependence of proton conductivity on humidity for cellulose nanofiber (CNF), cellulose nanocrystal $(\mathrm{CNC})$ paper, and Nafion at $30^{\circ} \mathrm{C}$. (B) Arrhenius plot at $100 \% \mathrm{RH}$. Calculated activation energies are $15.8,23.0$ and $20.4 \mathrm{~kJ} \cdot \mathrm{mol}^{-1}(0.16$, 0.24 and $0.21 \mathrm{eV}$ ) for Nafion, CNC and CNF respectively. Redrawn from Bayer et al. (2016) American Chemical Society.

for practical applications. As such, modification of cellulose to improve the conductivity is necessary. This is discussed in the following sections.

\section{Polymer Blends With Nanocellulose}

Given the advantageous properties of nanocellulose, it was perhaps natural for it to be combined with conventional polymeric ionomers such as Nafion. For example, in 2015, Jiang et al. investigated the use of commercial $5 \mathrm{wt} . \%$ Nafion dispersions blended with bacterial cellulose (derived from Medusomyces gisevii). Composite Nafion/BC PEMs (Figure 5b) were prepared by casting and drying, and the cellulose to Nafion ratio was varied (Jiang et al., 2015). The inclusion of nanocellulose reportedly improved the mechanical strength, increasing the storage modulus from $220 \mathrm{MPa}$ for Nafion 115 , to $1000 \mathrm{MPa}$ for a 1:1 Nafion-cellulose blend. In 


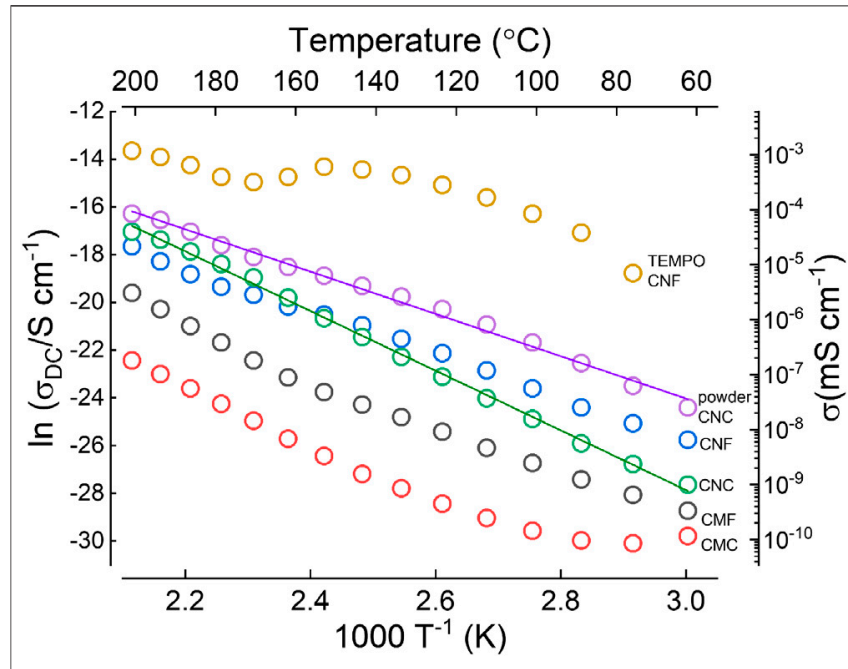

FIGURE 7 | Arrhenius plot of the DC conductivity of different cellulose samples measured as a function of temperature (after pre-heating samples at $110^{\circ} \mathrm{C}$, anhydrous conditions). The solid lines show the best fit of the Arrhenius equation to the experimental points with activation energy values, Ea, equal to $104 \mathrm{~kJ} \cdot \mathrm{mol}^{-1}(1.07 \mathrm{eV})$ for CNC film and $74 \mathrm{~kJ} \mathrm{~mol}^{-1}(0.76$ eV) for CNC powder. Redrawn from (Jankowska, et al., 2018).

addition, the area swelling ratio was significantly decreased from $21 \%$ to $<10 \%$. However, the thermal stability of the composites was worse compared to pristine Nafion. Increasing the cellulose content decreased the proton conductivity, reflecting the much lower conductivity of cellulose, which likely contributed to a lower ion exchange capacity (Figure 8, $30^{\circ} \mathrm{C}, 100 \% \mathrm{RH}$ ). A PEMFC was fabricated, and a maximum power density of $106 \mathrm{~mW} \cdot \mathrm{cm}^{-2}$ was obtained for a $1: 7$ cellulose-Nafion blend. This was slightly higher than a reference PEMFC using a conventional Nafion 115 membrane $\left(100.8 \mathrm{~mW} \cdot \mathrm{cm}^{-2}\right)$, although this is difficult to reconcile with the lower conductivity measured in the blend membranes. In addition, the power density of the reference MEA is rather low compared to the literature, possibly because the measurements were carried out at room temperature, or because conditions were not optimized. Additionally, the methanol permeability was initially higher in the composite membranes than in pure Nafion, but decreased after thermal annealing. DMFCs were fabricated, and a maximum peak power density of $21.1 \mathrm{~mW} \cdot \mathrm{cm}^{-2}$ was reported at $80^{\circ} \mathrm{C}$ for the $1: 7$ composite membrane. However, the DMFC performance for pure Nafion was not reported for comparison.

Similarly, in 2016 Gadim et al. investigated 50:50 wt\% blends of Nafion and bacterial cellulose (Gadim et al., 2016). Membranes of $\sim 100 \mu \mathrm{m}$ thickness were fabricated by a relatively complex process involving infiltration of Nafion solution into a bacterial cellulose film. The highest in-plane proton conductivity they reported was $140 \mathrm{mS} \cdot \mathrm{cm}^{-1}$ at $90{ }^{\circ} \mathrm{C}$ (Figure 9B, circles), and the activation energies were in the range of $10-20 \mathrm{~kJ} \cdot \mathrm{mol}^{-1}$, i.e. comparable to Nafion. The authors therefore concluded that proton transport primarily occurs through Nafion pathways in the membrane. Interestingly, the composite membrane had worse

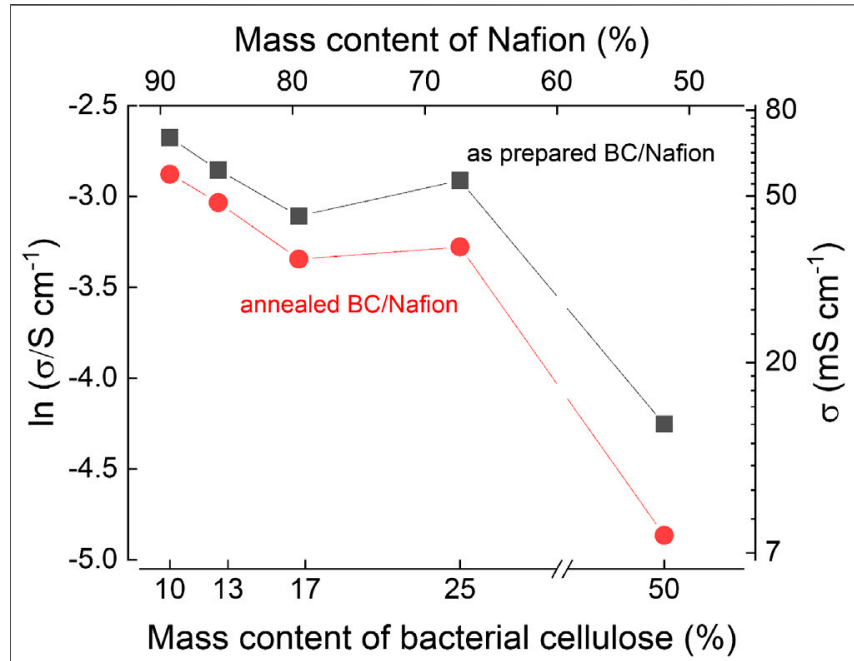

FIGURE 8 | Proton conductivity of BC/Nafion blend membranes before and after annealing, measured at $30^{\circ} \mathrm{C}$ and $100 \% \mathrm{RH}$. The observed trend indicates that when mixed with an ionomer, the conductivity depends on its relative proportion in the composite. Redrawn from Jiang et al. (2015).

thermal stability than the pure Nafion or cellulose components, attributed to catalytic degradation of cellulose by the sulfonic groups in Nafion. The composite membrane was assembled into a conventional MEA, obtaining maximum power density of just $16 \mathrm{~mW} \cdot \mathrm{cm}^{-2}$, despite the nominally high in-plane conductivity. This highlights the importance of measuring the ionic conductivity of PEMs through-plane if the results are to be relevant to fuel cell devices, optimization of the fuel cell fabrication and measurement protocols, and the measurement of suitable reference cells.

More recently, Wang et al. fabricated similar composite membranes by soaking conventional cellulosic filter papers in Nafion (Wang, et al., 2019). The through-plane conductivity estimated from fuel cell tests was $15 \mathrm{mS} \cdot \mathrm{cm}^{-1}$ at $90{ }^{\circ} \mathrm{C}$ and $100 \% \mathrm{RH}$. This is relatively low compared to the above study (Gadim et al., 2016), but this can be attributed in part to the difference between in-plane and through-plane conductivity measurements. Despite this, the conductivity is surprisingly low for a Nafion-containing PEM. The corresponding activation energy was $11.6 \mathrm{~kJ} \cdot \mathrm{mol}^{-1}(0.12 \mathrm{eV})$, attributed to the Grotthuss mechanism through the Nafion. MEAs fabricated from these membranes exhibited an output power of $23 \mathrm{~mW} \cdot \mathrm{cm}^{-2}$ at $80{ }^{\circ} \mathrm{C}$.

Other polymer blends have also been investigated. For example, in 2014, Gadim et al. synthesized poly(4-styrene sulfonic acid) (PSSA) in situ on a bacterial cellulose support (derived from Gluconacetobacter sacchari), using poly(ethylene glycol) diacrylate as a crosslinker (Gadim et al., 2014). The assumed polymer structure is depicted in Figure 9A. Different ratios of the component materials were investigated, and the membrane thickness ranged from 50 to $300 \mu \mathrm{m}$. The highest through-plane proton conductivity $\left(\sim 130 \mathrm{mS} \cdot \mathrm{cm}^{-1}\right)$ and ion 


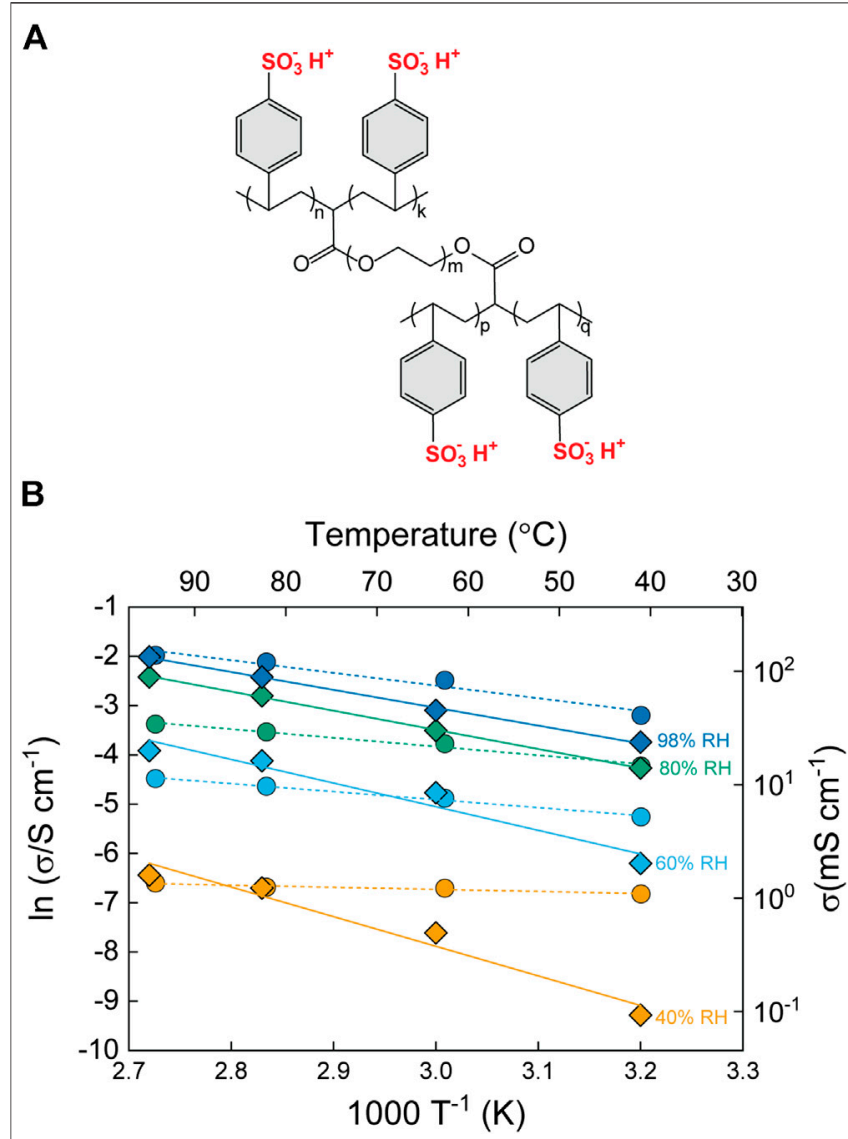

FIGURE 9 | (A) The chemical structure of polystyrene sulfonate crosslinked with PEGDA, which was used to prepare a composite membrane with bacterial nanocellulose. (B) Arrhenius plot of the in-plane conductivity of a Nafion $囚 / B C(1: 1)$ composite membrane for different relative humidities (circular data points), and of a crosslinked PSS/BC composite membrane ( 17 wt\% BC) (diamond data points). The results show typical ionomer-like behavior, with a strong dependence on humidity and weaker dependence on temperature. Redrawn from Gadim et al. (2014). Gadim et al. (2016).

exchange capacity $\left(2.25 \mathrm{mmol} \mathrm{g}^{-1}\right)$ were obtained at $94{ }^{\circ} \mathrm{C}$ and $98 \% \mathrm{RH}$, with $\sim 17 \mathrm{wt} \%$ bacterial cellulose content. The conductivity was dependent on both the humidity and temperature, as shown in Figure 9B (diamonds), corresponding to an activation energy of $30 \mathrm{~kJ} \cdot \mathrm{mol}^{-1}$ at $98 \%$ $\mathrm{RH}$. The authors attributed this high activation energy to stronger binding of protons as a result of the much higher concentration of sulfonic acid groups relative to Nafion. However, at this stage, the group did not manufacture an electrochemical device based on their findings. A follow-up study by the same group in 2017 investigated the difference between in-plane and through-plane conductivity measurements for PSSA/BC membranes (Gadim, et al., 2017). The in-plane conductivity at low RH was found to be almost 5 times higher than in through-plane configuration. This can be attributed to the anisotropy of cellulose fibers, which lay preferentially in the plane of the membranes. As such, there are many more discontinuous interfaces between BC and PSSA, corresponding to higher resistance for through-plane measurements. At higher $\mathrm{RH}$ and temperature the value of $\sigma_{\|} / \sigma_{\perp}$ value decreased to $\sim 1.2$, suggesting the importance of water not only for faster proton transport but also for the formation of continuous conductive phase. We directly compare the different studies on Nafion and PSSA blends by Gadim et al. on the same plot in Figure 9B (circles and diamonds, respectively). The marked difference in the fitted slopes corresponds to different activation energies for the $\mathrm{BC} / \mathrm{Nafion}$ $\left(3.5,13.5,14.721 .4 \mathrm{~kJ} \cdot \mathrm{mol}^{-1}\right.$ increasing with increasing $\left.\mathrm{RH}\right)$ and BC/PSSA membranes $\left(50.0,39.9,32.3,30.2 \mathrm{~kJ} \cdot \mathrm{mol}^{-1}\right.$, decreasing with increasing $\mathrm{RH}$ ). This in turn indicates that different conduction mechanisms are responsible for proton conduction, i. e, conventional Grotthuss-type water-mediated transport in Nafion-based composites, and a greater contribution from surface transport in the PSSA composites.

In a parallel study, the same group investigated composites of the same bacterial cellulose with a different polymer, namely poly(methacryloyloxyethyl)phosphate (PMOEP) (Figure 10A) (Vilela et al., 2016). Again, the in-plane proton conductivity was strongly dependent on ratio of PMOEP, as well as the relative humidity (Figure 10B). The best performance was achieved for a composite PEM with $52 \mathrm{wt} \%$ cellulose. This sample had improved mechanical properties compared to pure PMOEP, with a Young's Modulus of $7.8 \mathrm{GPa}$ and a tensile strength of $33 \mathrm{MPa}$. Meanwhile, the proton conductivity was quite high in the fully hydrated state $\left(>100 \mathrm{mS} \mathrm{cm}^{-1}\right)$, but it should be noted that this is the in-plane and not the throughplane conductivity. The authors attributed the conductivity to the phosphoric acid groups in the PMOEP, high water uptake (206\%), and a high ion exchange capacity (IEC, $3.38 \mathrm{mmol}$ $\left.\left[\mathrm{H}^{+}\right] \mathrm{g}^{-1}\right)$. The activation energies were quite high, ranging from 15 at high $\mathrm{RH}$ to $40 \mathrm{~kJ} \cdot \mathrm{mol}^{-1}$ at low $\mathrm{RH}$. The authors attribute this generally to a "structural proton diffusion" mechanism. Presumably, the lower activations energies indicate Grotthuss-type water-mediated conduction, whereas the higher activation energies correspond to surface hopping in low humidity environment. An important conclusion of this study was that pure PMOEP cannot normally be used as a PEM, but blending it with cellulose potentially enables it to be used in this application. This technique may therefore be useful for other hitherto unexplored proton conducting materials.

In $2018, \mathrm{Ni}$ et al. blended carboxylated and sulfonated poly(aryl ether ketone) (SPAEK) with 2-10 wt\% sulfonic acid functionalized $\mathrm{CNC}$, mainly as a structural reinforcement (Ni et al., 2018). The in-plane conductivity of SPAEK is already very high (i.e. $204 \mathrm{mS} \cdot \mathrm{cm}^{-1}$ at $90{ }^{\circ} \mathrm{C}$ and $98 \%$ $\mathrm{RH}$ ), and blending with cellulose did not have a significant effect $\left(173-218 \mathrm{mS} \cdot \mathrm{cm}^{-1}\right)$. The inclusion of CNC did improve the tensile strength from $24 \mathrm{MPa}$ for pure SPAEK, to $32.3 \mathrm{MPa}$ for $10 \mathrm{wt} \%$ blends. Similarly, the Young modulus increased from 701 to $828 \mathrm{MPa}$, respectively. In another similar study, the same group blended sulfonated CNC with sulfonated fluorenyl-containing poly(ether ether ketone ketone) (SFPEEKK) (Ni et al., 2018). The use of $4 \mathrm{wt} \% \mathrm{CNC}$ resulted in a remarkably high proton conductivity of $245 \mathrm{mS} \cdot \mathrm{cm}^{-1}$ at $90{ }^{\circ} \mathrm{C}$, i.e. $\sim 60 \%$ higher than for pure SFPEEKK. The authors attributed this to the formation of a 


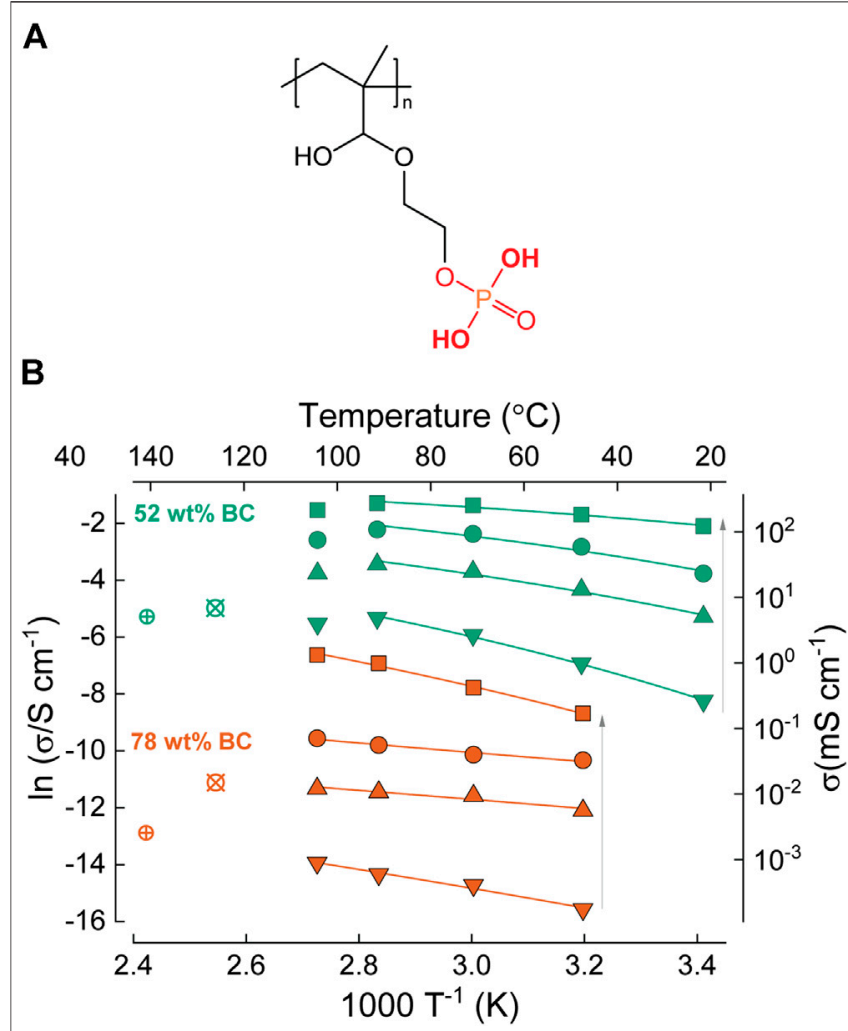

FIGURE 10 | (A) Chemical structure of poly(methacryloyloxyethyl) phosphate (PMOEP). (B) Arrhenius plot of the in-plane conductivity of $\mathrm{BC} /$ PMOEP PEMs containing 52 wt\% BC (green data points) or 78 wt\% BC (orange data points) at increasing relative humidity of $30,60,80$ and 98 \% (indicated by arrows). Å and Ä symbols correspond to the operating conditions $140^{\circ} \mathrm{C} / 20 \% \mathrm{RH}$, and $120^{\circ} \mathrm{C} / 50 \% \mathrm{RH}$, respectively. Redrawn from Vilela et al. (2016).

hydrogen bonding network between the sulfonic groups of the polymer and the hydroxyl groups of cellulose, forming proton conduction pathways. Increasing the cellulose content to $10 \mathrm{wt}$ $\%$ seems to have negated this beneficial effect, and the conductivity fell to below that of SFPEEKK.

Meanwhile, Wang et al. blended cellulose with resorcinol bis(diphenyl phosphate) (RDP, Figure 11A) (Wang et al., 2019). This polymer reportedly binds to cellulose via hydrogen bonds, enriching the surface with $-\mathrm{PO}_{3}{ }^{-} \mathrm{H}$ functionalities, and promoting proton transport. The membranes were prepared by soaking conventional cellulose filter papers in RDP dispersions. The through-plane conductivity (Figure 11B) was estimated from fuel cell tests to be $10 \mathrm{mS} \cdot \mathrm{cm}^{-1}$ at $90^{\circ} \mathrm{C}$ and $100 \% \mathrm{RH}$, and the activation energy was $18.3 \mathrm{~kJ} \cdot \mathrm{mol}^{-1}(0.19 \mathrm{eV})$, attributed to surface-mediated proton-hopping along hydroxyl functional groups. Fourier transform infrared spectroscopy (FTIR) was used to confirm that the relatively high activation energy is due to weaker hydrogen bonding compared to Nafion. An MEA fabricated from $\mathrm{RDP} /$ cellulose blend membranes exhibited maximum power density of $10 \mathrm{~mW} \cdot \mathrm{cm}^{-2}$ at $60^{\circ} \mathrm{C}$, which was slightly lower than equivalent Nafion/cellulose blends (as discussed above).

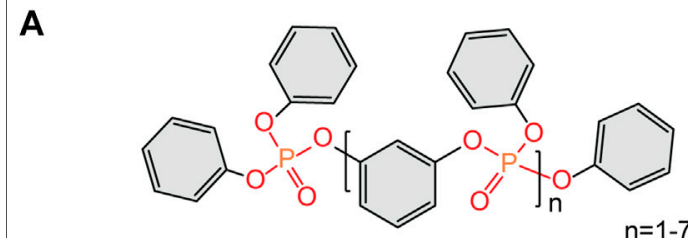

B

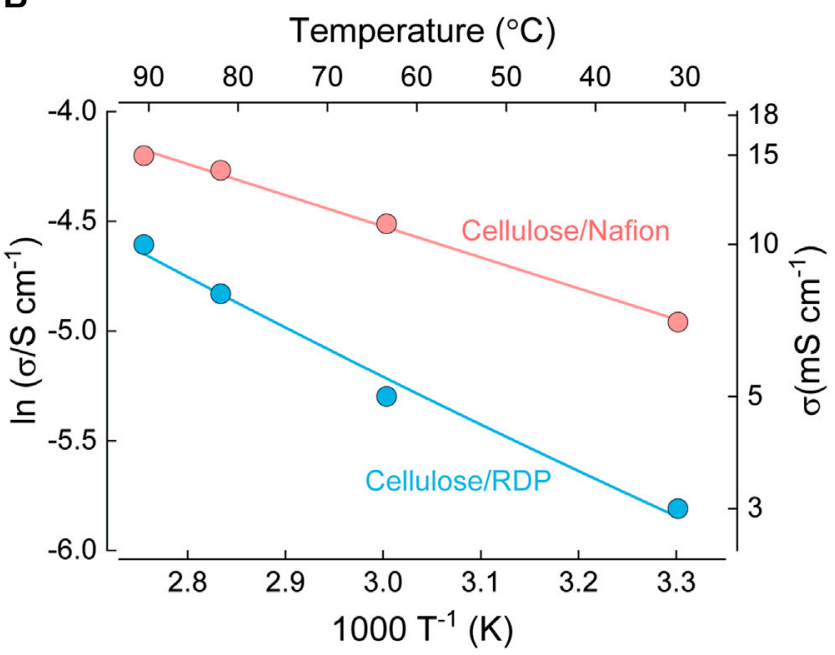

FIGURE 11 | (A) Chemical structure of resorcinol bis(diphenyl phosphate) (RDP). (B) Arrhenius plot showing the conductivity and activation energy of cellulose/Nafion and cellulose/RDP membranes. Redrawn from Gadim et al. (2016), Wang et al. (2019).

Similar trends and conclusions have been obtained in other works, including $\mathrm{CNF}$ fibers spun via solution blowing, surface modified with imidazole and finally blended with sulfonated polyether sulphone ( $5 \mathrm{wt} \%$ of modified CNF in SPES) (Di and Yin, 2019); phosphoric acid-doped CNF in sulfonated poly (ether sulfone), SPES (Cai et al., 2018); CNC blended with sulfophenylated polyether ether ketone (SPEEKK) additionally coated by silica (Zhao et al., 2019); and amino acid clusters supported by CNFs (Zhao et al., 2019).

Several interesting works have been recently reported from the University of Aveiro, in Portugal. Firstly, wet BC membranes were mixed with fucoidan (a sulphated polysaccharide found in algae) and tannic acid as a crosslinker, followed by heating at $105^{\circ} \mathrm{C}$ for $24 \mathrm{~h}$ (Vilela et al., 2020). The resulting membranes had thicknesses of 52 and $79 \mu \mathrm{m}$ and were reportedly thermally stable up to $200^{\circ} \mathrm{C}$, even in oxygen containing atmosphere. Meanwhile, the highest through-plane conductivity was $1.6 \mathrm{mS} \cdot \mathrm{cm}^{-1}$, for the highest fucoidan content (75 wt\%). The activation energies ranged from 16 to $63 \mathrm{~kJ} \cdot \mathrm{mol}^{-1}, \quad 32-69 \mathrm{~kJ} \cdot \mathrm{mol}^{-1}$ and $54-74 \mathrm{~kJ} \cdot \mathrm{mol}^{-1}$ for unmodified BC, $50 \mathrm{wt} \%$ and $75 \mathrm{wt} \%$ fucoidan, respectively. These values were strongly dependent on RH and are relatively high compared to Nafion - the authors attribute this to a mixture of Grotthuss-type and vehicle-type proton conduction. Whilst the authors attribute the improved conductivity directly to inclusion of fucoidan, the potentially important role of tannic acid was not considered, despite the abundance of - $\mathrm{OH}$ groups which could 
assist proton transport. Although the conductivity in this work is relatively low, this work demonstrates the possibility of fabricating PEMs using entirely natural precursors. We expect more research in this area due to increasing needs to use renewable and abundant natural compounds for materials design.

Finally, lignin is a complex biopolymer which can be modified with sulfonic acid $\left(-\mathrm{SO}_{3} \mathrm{H}\right)$, making it potentially useful as an ionomer (Farzin et al., 2020). As such, Vilela et al. combined the sodium salt of lignosulfonic acid with a BC membrane (thickness $85 \mu \mathrm{m}$ ), in addition to crosslinking with tannic acid (Vilela et al., 2020). The resulting ionic conductivity measured in-plane was $23 \mathrm{mS} \cdot \mathrm{cm}^{-1}$ (BC:LS = 4:3 wt), although it should be noted that acid ion exchange was not performed, and therefore this is attributed to sodium ion conduction, with a possible contribution from protons at high $\mathrm{RH}$.

Overall, blending cellulose with proton conducting polymers has several benefits. As well as improving the mechanical strength, low loadings of nanocellulose can reportedly enhance proton conductivity by establishing new proton transport pathways through the host polymer, although this is rather speculative at present. For higher cellulose contents, the conductivity simply decreases in proportional to the host polymer ionomer content. More studies on the effect of cellulose blends on the hydrogen gas permeability, methanol permeability and fuel cell performance would be welcomed.

\section{Chemical Modification of Cellulose}

From a sustainability point of view, completely avoiding the utilization of fluorinated polymers or other toxic and/or expensive ionomers is preferred. However, as discussed above, pure nanocellulose membranes don't have sufficient intrinsic proton conductivity to satisfy the targets set for PEMFC applications by the US Department of Energy ${ }^{3}$ or Fuel Cell Commercialization Conference of Japan (Ohma et al., 2011). A promising alternative to using additives is to directly modify the chemical structure of the cellulose polymer to improve the desired properties. Due to the presence of reactive hydroxyl groups in the structure of cellulose (especially the primary alcohol group $-\mathrm{CH}_{2} \mathrm{OH}$ ) such modification can be performed in a variety of different ways, as has been demonstrated historically. For example, surface modification of cellulosic materials improves the efficiency of the defibrillation process, or can be used to make them compatible with specific solvents (Thomas et al., 2018). The most common approaches towards modifying the primary alcohol group of cellulose are carboxymethylation, 2,2,6,6-tetramethylpiperidine-1-oxylmediated (TEMPO-mediated) oxidation, phosphorylation and sulfonation. In the field of PEM development, various forms of sulfonation have been used to improve the proton conductivity.

In the first study of this kind, Seo et al. (2009) used crosslinking of conventional microcrystalline cellulose fibers with sulfonic acid linkers as a method of increasing the proton conductivity by introducing proton donating acid groups. For

${ }^{3} \mathrm{DOE}$ technical targets, https://www.energy.gov/eere/fuelcells/doe-technicaltargets-polymer-electrolyte-membrane-fuel-cell-components this purpose, they blended sulfosuccinic acid (from 5 to $30 \mathrm{wt} \%$ ) with cellulose dissolved in dimethyl sulfoxide (DMSO) and fabricated the membranes by solution casting in Teflon dishes. The membranes were dried for 2 days at $80^{\circ} \mathrm{C}$ and annealed at $120{ }^{\circ} \mathrm{C}$ to promote the crosslinking reaction (Figure 12A), although the thickness was not reported. They succeeded in significantly improving the in-plane conductivity, reaching $\sim 40 \mathrm{mS} \cdot \mathrm{cm}^{-1}$ at moderate temperatures (although the conductivity of unadulterated cellulose was not included for comparison). Importantly, the increase of conductivity was exponentially proportional to the loading of acid in the membrane (Figure 12B), however the conductivity of unchanged cellulose was not reported. The activation energies were calculated to be $11.8 \mathrm{~kJ} \cdot \mathrm{mol}^{-1}(\sim 0.1 \mathrm{eV})$, similar to Nafion (Figure 12C). However, it should be noted that the conductivity measurements were performed in-plane, rather than the more relevant through-plane configuration.

Meanwhile, Yang et al. investigated bacterial cellulose PEMs derived from A. Xylinum NUST4.2 (Yang et al., 2009). To improve the conductivity, chemical modification with phosphotungstic acid (PWA) was performed. Electrocatalyst layers were fabricated by chemical reduction of hexachloroplatinic acid on bacterial cellulose fibers in dispersion, followed by freeze drying. This material was then blended with water, isopropanol, and acetylene black to form an electrocatalyst ink, which was brushed onto both sides of the PEM. Unfortunately, the proton conductivity was not reported, but the fabricated MEA achieved a power density of $12.1 \mathrm{~mW} \cdot \mathrm{cm}^{-2}$ at $40{ }^{\circ} \mathrm{C}$. The improved performance compared to the similar study by Evans et al. (Evans et al., 2003) may be attributed to the use of acetylene black to improve electronic conductivity in the electrocatalyst layer, and acid modification of the membrane to improve proton conductivity.

In 2013 Lin et al. grafted 2-acrylamido-2-methyl-1propanesulfonic acid (AMPS) onto the surface of bacterial cellulose using UV-light induced polymerization. Three types of membrane were fabricated with the different degrees of grafting, i.e. 5.6, 28.6 and $39.5 \mathrm{wt} \%$ (unspecified thickness). The corresponding through-plane proton conductivities in the fully hydrated state were $\sim 2,18$ and $29 \mathrm{mS} \cdot \mathrm{cm}^{-1}$, respectively (whilst Nafion-115 showed ca. $39 \mathrm{mS} \cdot \mathrm{cm}^{-1}$ under identical conditions). The fuel cell power density improved with increasing temperature, reaching a maximum of $97 \mathrm{~mW} \cdot \mathrm{cm}^{-2}$ at $50^{\circ} \mathrm{C}$ (Lin et al., 2013).

Some forms of CNC contain sulfonic acid groups, which happen to be introduced via acid hydrolysis during synthesis. Bayer et al. measured the through-plane proton conductivity of PEMs fabricated from CNCs to be $4.6 \mathrm{mS} \cdot \mathrm{cm}^{-1}$ at $120^{\circ} \mathrm{C}$ (Bayer et al., 2016). This was much higher than that of equivalent CNF membranes, and was attributed to the presence of these sulfonic acid groups. In addition, CNC membranes also had slightly improved gas barrier properties compared to $\mathrm{CNF}$ membranes, due to the more densely packed microstructure. A PEMFC was assembled using a $30 \mu \mathrm{m}$ thick CNC membrane, and a maximum power density of $17.2 \mathrm{~mW} \cdot \mathrm{cm}^{-2}$ was obtained at $80{ }^{\circ} \mathrm{C}$ and $95 \% \mathrm{RH}$. 
A

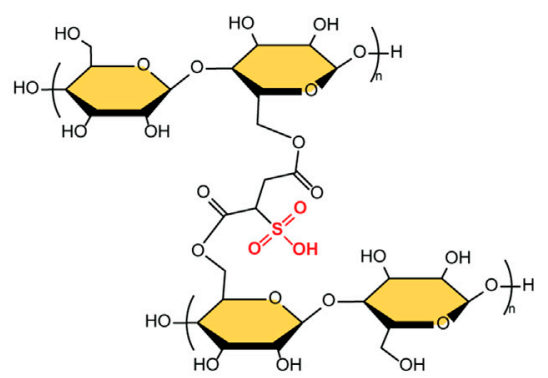

C

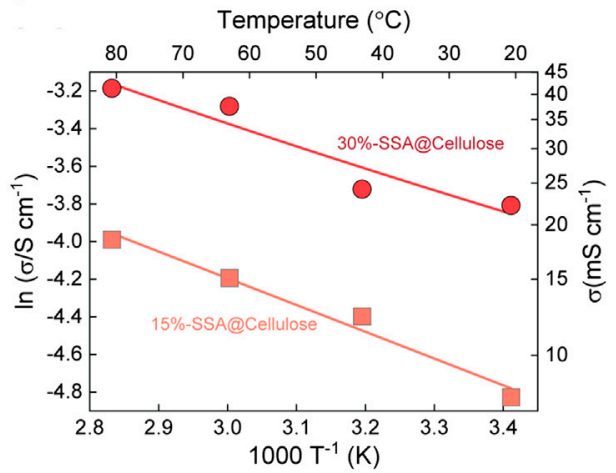

B

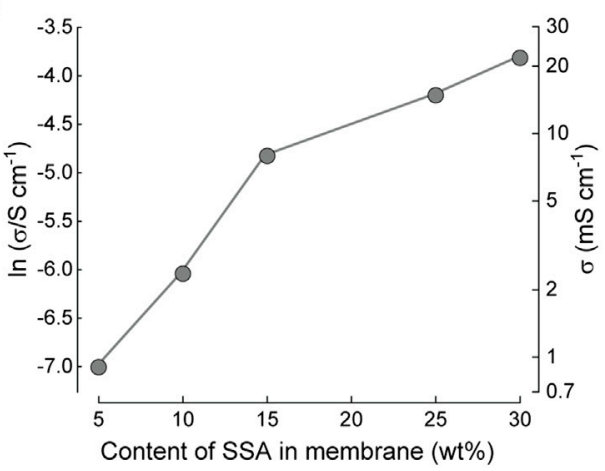

D

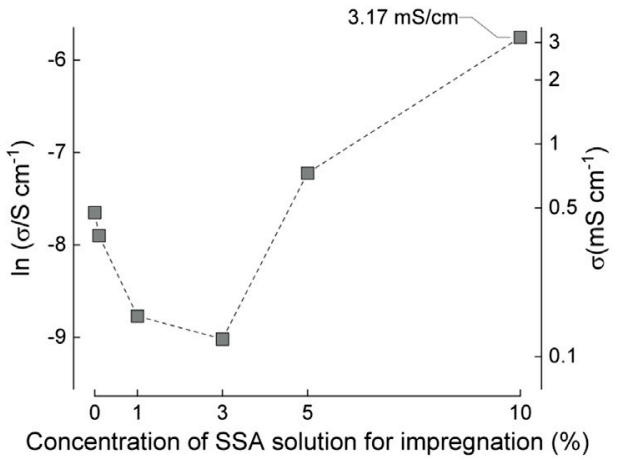

FIGURE 12 | (A) Chemical reaction for the preparation of sulfosuccinic acid (SSA) cross-linked cellulose membranes. (B) Proton conductivity of cellulose/SSA membranes as a function of crosslinker concentration. (C) Temperature-dependent proton conductivity of cellulose/SSA membranes with 30\% and 15\% of sulfosuccinic acid. Redrawn from Seo et al. (2009). (D) Proton conductivity of CNF/SA membranes as a function of SSA solution concentration used for impregnation Redrawn from Sriruangrungkamol and Chonkaew (2020).

Similarly, Jankowska et al. reported that $500 \mu \mathrm{m}$ thick TEMPO-oxidized nanocellulose membranes had significantly higher intrinsic conductivity in anhydrous conditions $\left(1.7 \times 10^{-4} \mathrm{mS} \mathrm{cm}^{-1}\right.$ at $\left.100{ }^{\circ} \mathrm{C}\right)$ compared to unmodified nanocellulose $\left(1.2 \times 10^{-7} \mathrm{mS} \mathrm{cm}^{-1}\right.$ ) (Jankowska et al., 2018), attributed to the additional surface carboxyl groups (as confirmed by FT-IR). However, it was not specified if these were through-plane or in-plane measurements, and parameters such as the ion exchange capacity were not included in this work.

Meanwhile, in 2019 Guccini et al. prepared carboxylated CNFs by TEMPO-mediated oxidation of cellulose pulp, followed by mechanical fibrillation, casting into membranes, and sodium ion exchange with protons in sulfuric acid (Guccini et al., 2019). The proton conductivity was estimated from the in-situ fuel cell measurements $\left(30{ }^{\circ} \mathrm{C}\right.$ and $95 \% \mathrm{RH}$ ) to be $\sim 1.3 \mathrm{mS} \cdot \mathrm{cm}^{-1}$ for low surface charge $\left(600 \mu \mathrm{mol} \cdot \mathrm{g}^{-1}\right)$ and slightly higher at $\sim 1.5 \mathrm{mS} \cdot \mathrm{cm}^{-1}$ for high surface charge $\left(1550 \mu \mathrm{mol} \cdot \mathrm{g}^{-1}\right)$.

Despite being thinner, all membranes displayed significantly smaller crossover current compared to Nafion, attributed to the gas barrier properties of nanocellulose. The number of water molecules per proton conducting site was found to be more than 100 times higher than in Nafion-212, suggesting that water bound to the CNF surface plays a critical role in proton transport, enabling operation even at low RH. Such behavior is somewhat different from other works (e.g. Bayer et al., 2016) and may indicate an important advantage of the chemical modification of CNFs with weak acids.

Recent work took a similar approach to Seo et al. (2009), crosslinking cellulose nanofibers rather than conventional cellulose with sulfosuccinic acid (Sriruangrungkamol and Chonkaew, 2020). CNF membranes $(20 \mu \mathrm{m}$ thick $)$ were incubated in SSA solution for 3 days, followed by drying and hot pressing at $120 \mathrm{C}$. This resulted in an increase in throughplane proton conductivity from $0.48 \mathrm{mS} \cdot \mathrm{cm}^{-1}$ for the unmodified CNF membrane, to $3.17 \mathrm{mS} \cdot \mathrm{cm}^{-1}$ after impregnation in $10 \% \mathrm{SSA}$ solution and crosslinking. Meanwhile, there was a significant decrease in the methanol permeability compared to Nafion, indicating the potential suitability of these membranes for use in in DMFCs. However, counterintuitively, despite crosslinking, the tensile strength, and the oxidative stability of the CNF/SSA membranes were significantly worse than compared to pristine CNF. This demonstrates that the chemical structure of the cellulose was likely damaged during the reaction with the acid.

Overall, functionalization of cellulosic materials with acidic groups can be an effective, convenient, and cheap way to improve the proton conductivity. 


\section{Nanocellulose Blends With Small Molecules}

Whilst chemical modification has proven to be effective in improving the proton conductivity of nanocellulose, the steps involved in adding functional groups can be time consuming and costly. As such, there have been several works investigating the simple addition of small molecules to cellulose in order to improve the conductivity.

For example, in 2012, Jiang et al. immersed BC membranes $(40-60 \mu \mathrm{m})$ in phosphoric or phytic acids of different concentrations, dramatically improving the in-plane proton conductivity and resulting in good mechanical properties and high thermal stability (Jiang, et al., 2012). The conductivity increased with dopant concentration, reaching a maximum of $110 \mathrm{mS} \cdot \mathrm{cm}^{-1}$ at $80{ }^{\circ} \mathrm{C}$ for phosphoric acid $\left(6 \mathrm{~mol} \mathrm{~L}^{-1}\right)$, and $90 \mathrm{mS} \cdot \mathrm{cm}^{-1}$ at $60{ }^{\circ} \mathrm{C}$ for phytic acid $\left(1.6 \mathrm{~mol} \mathrm{~L}{ }^{-1}\right)$ (Figure 13). Meanwhile, the reported activation energies were surprisingly low, at $4.02 \mathrm{~kJ} \cdot \mathrm{mol}^{-1}$ and $11.29 \mathrm{~kJ} \cdot \mathrm{mol}^{-1}$, respectively. Fuel-cell tests at ambient temperature were performed and maximum power densities of 17.9 and $23.0 \mathrm{~mW} \cdot \mathrm{cm}^{-2}$ were achieved for $8 \mathrm{M}$ phosphoric acid and $1.6 \mathrm{M}$ phytic acid doped membranes, respectively. These values were much lower than for Nafion, despite comparable conductivity. The authors admit that leaching of the acid during the fuel cell testing in humid conditions may be a problem, and suggested that this may be prevented by e.g. by crosslinking.

In a different approach, Smolarkiewicz et al. blended unmodified microcrystalline cellulose with proton conducting imidazole molecules $(\sim 7.5 \mathrm{wt} \%)$. Thick $(1.15 \mathrm{~mm})$ pellets of this material were measured to have a proton conductivity of $0.002 \mathrm{mS} \mathrm{cm}^{-1}$ at $160{ }^{\circ} \mathrm{C}$ under anhydrous conditions. This was stated to be four orders of magnitude higher than the unmodified reference sample, although it was not entirely clear from the experimental details if the conductivity was measured in-plane or through-plane (Smolarkiewicz, et al., 2014).

Combining imidazole with $\mathrm{CNC}$ resulted in proton conductivity three orders of magnitude higher compared to when microcrystalline cellulose was used. This was attributed to the improved dispersibility of $\mathrm{CNC}$ in water, allowing for higher imidazole concentration in the PEMs. The highest through-plane proton conductivity (i.e. $4.0 \mathrm{mS} \mathrm{cm}{ }^{-1}$ at $160{ }^{\circ} \mathrm{C}$ in anhydrous conditions) was obtained for a molar ratio of 1.3 between the glucose units of CNC and the imidazole molecules (corresponding to an estimated $22 \mathrm{wt} \%$ imidazole) (Tritt-Goc, et al., 2019; TrittGoc, et al., 2018). Figure 14A summarizes the anhydrous proton conductivity of CNC composites with imidazole or triazole, as a function of temperature. The reported activation energies were $83.0 \mathrm{~kJ} \mathrm{~mol}^{-1}, 72.4 \mathrm{~kJ} \mathrm{~mol}^{-1}, 56.0 \mathrm{~kJ} \mathrm{~mol}^{-1}$ and $75.7 \mathrm{~kJ} \mathrm{~mol}^{-1}$ for the CNC, $2.66 \mathrm{CNC}-\mathrm{Tri}, 1.17 \mathrm{CNC}-\mathrm{Im}$ and 1.3 CNC-Im respectively (Tritt-Goc, et al., 2019; Tritt-Goc, et al., 2020). An important feature of the latter study is that "desulfonated" CNC was used to fabricate the composites, meaning that a fairer comparison could be made. The conductivity peaks at temperatures $>150{ }^{\circ} \mathrm{C}$, suggesting that this method is promising for intermediate temperature fuel cell applications.

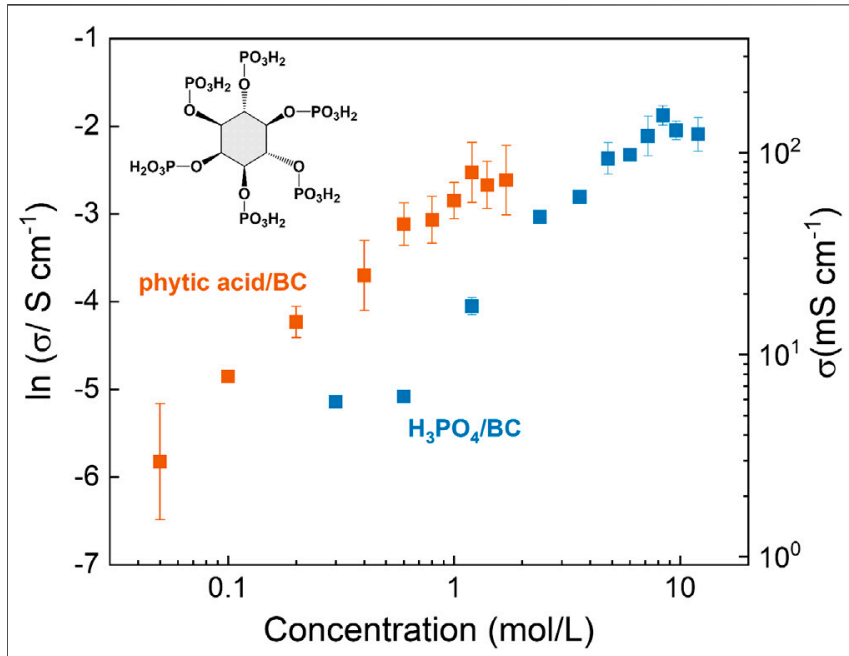

FIGURE 13 | In-plane proton conductivity of BC membranes doped with different amounts of phytic or phosphoric acid as a function of acid concentration in the impregnation solution. The inset shows the chemical structure of phytic acid. Redrawn from Jiang et al. (2012).

The highest reported performance for this class of composite PEM was obtained for CNC mixed with polyvinyl alcohol (PVA) and 1,2,4-triazole. The anhydrous through-plane proton conductivity was determined to be of $13 \mathrm{mS} \mathrm{cm}^{-1}$ at $120{ }^{\circ} \mathrm{C}$, for a membrane with $23 \mathrm{wt} \% \mathrm{CNC}, 57 \mathrm{wt} \% \mathrm{PVA}$, and $20 \mathrm{wt} \%$ triazole (Etuk et al., 2020). In this case, concentrated sulfuric acid was added during the membrane synthesis, and therefore sulfonation cannot be ruled out as having a synergistic effect with the presence of triazole in improving the proton conductivity. However, due to a lack of suitable reference samples in this study it is difficult to draw clear conclusions about the proton conduction mechanisms.

Protic ionic liquids (PIL) mixed with the bacterial cellulose have also been proposed. In 2018, Rogalsky et al. combined BC (derived from Komagataeibacter intermedius IMBG291) with a newly synthesized PIL, namely, N-butylguanidinium tetrafluoroborate $\left(\mathrm{BG}_{-} \mathrm{BF}_{4}\right)$ (Rogalsky et al., 2018). This PIL is an excellent proton conductor in its own right at high temperatures, reaching $180 \mathrm{mS} \mathrm{cm}{ }^{-1}$ at $180{ }^{\circ} \mathrm{C}$. Several types of membranes were fabricated, and the dependance of the anhydrous through-plane conductivity on temperature is shown in Figure 14B. At $60 \mathrm{wt} \% \mathrm{BG}_{-}-\mathrm{BF}_{4}$ loading, a high tensile strength of $35 \mathrm{MPa}$ was measured, but the proton conductivity was fairly low, reaching a maximum of

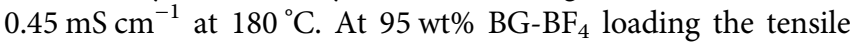
strength dramatically decreased to $6 \mathrm{MPa}$, as expected for such low BC content of just $5 \mathrm{wt} \%$. However, the conductivity was two orders of magnitude higher, at $52 \mathrm{mS} \mathrm{cm}^{-1}$. This is still more than three times lower than the conductivity of the pure PIL. In order to further improve the conductivity and mechanical strength, the BC was additionally modified with polyaniline (PANI), increasing the maximum conductivity to $100 \mathrm{mS} \mathrm{cm}^{-1}$ for a 


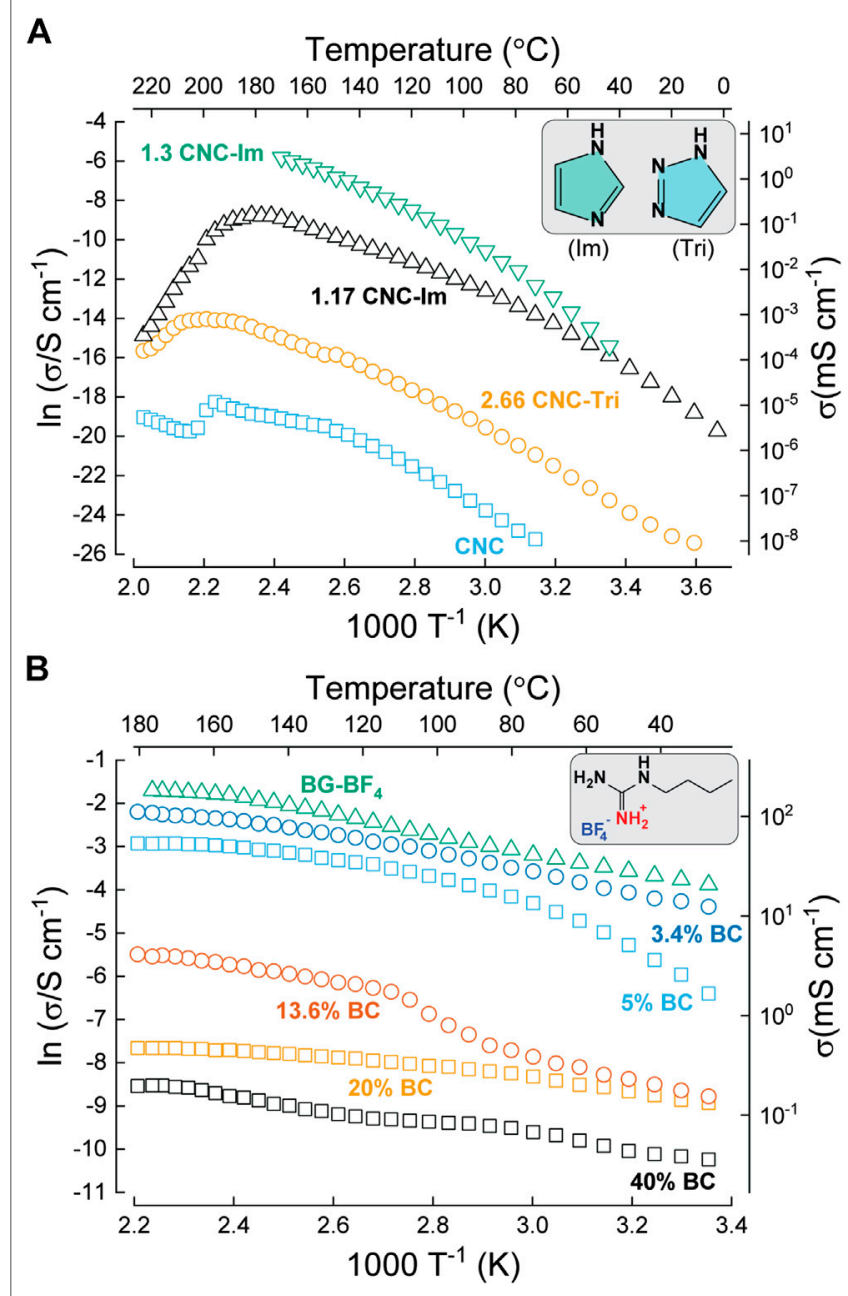

FIGURE 14 | Temperature-dependent proton conductivity in anhydrous conditions. (A) CNC blended with imidazole and $1 \mathrm{H}-1,2,3$-triazole (structures shown inset). Redrawn from Tritt-Goc et al. (2019). Tritt-Goc et al. (2020). (B) Bacterial cellulose impregnated with the protic ionic liquid $\mathrm{N}$-butylguanidinium tetrafluoroborate (BG-BF4, structure shown inset). Redrawn from Rogalsky et al. (2018).

BC/PANI-BG-BF 4 composite containing $3.4 \mathrm{wt} \%$ BC (Rogalsky et al., 2018). The activation energy for $\mathrm{BC} / \mathrm{PANI}-\mathrm{BG}-\mathrm{BF}_{4}$ membranes $\left(95 \% \mathrm{BG}-\mathrm{BF}_{4}, 3.4 \% \mathrm{BC}\right)$ was reported to be $18 \mathrm{~kJ} \cdot \mathrm{mol}^{-1}$, close to pure $\mathrm{BG}-\mathrm{BF}_{4}\left(17 \mathrm{~kJ} \cdot \mathrm{mol}^{-1}\right)$. However, the membrane with lower $\mathrm{BG}-\mathrm{BF}_{4}$ content $\left(80 \% \mathrm{BG}-\mathrm{BF}_{4}, 13.6 \% \mathrm{BC}\right)$ showed more complex behavior. Three different regions with activation energies of $19.6,45.2$ and $20.4 \mathrm{~kJ} \cdot \mathrm{mol}^{-1}$ were observed at low, medium, and high temperature regions respectively. The authors suggested that the Grotthuss mechanism is dominant in every case and these changes in activation energy are attributed to the formation of a solvated interface between PIL and BC/PANI fibrils (Figure 14B).

Doping cellulosic materials with suitable small molecules appears at first to be a convenient, method to dramatically improve proton conductivity, as well as potentially increasing the operating temperature of fuel cells. However, a likely drawback not sufficiently discussed in the works reported to date is the durability. Small molecules such imidazole can evaporate from the host material at elevated temperature, and thus the conductivity will decrease with every heating cycle (TrittGoc et al., 2020). Additionally, the compounds such as imidazole and triazole are water-soluble, and unless they are sufficiently immobilized they will wash out of the membrane with the water produced at the cathode, further decreasing the conductivity during operation. As such, future studies should focus much more seriously on measuring durability and the membrane degradation mechanisms. In addition, stabilization of these small molecules by e.g. polymerization or dispersion in a suitable polymeric host is of interest. Finally, many of the above-discussed measurements were conducted in anhydrous conditions or in-plane configuration, and therefore investigation of this class of membranes in conditions more typical for fuel cells is required.

\section{CRITICAL OVERVIEW}

The proton conductivities of cellulosic materials reported in the studies discussed above are newly summarized and compared directly in Figure 15, as a function of the cellulose content. Whilst the results are often measured under quite different conditions (e.g. at different temperatures, in humidified or anhydrous conditions, in-plane or through-plane configuration) some broad trends can be extracted. By analyzing this plot, we can make several important conclusions.

i. The conductivity of unadulterated cellulosic materials (circular data points) such as BC, CNF, and "desulfonated" CNC membranes is very low (i.e. < $0.1 \mathrm{mS} \mathrm{cm}^{-1}$ ), and therefore probably not suitable for ionomer applications without some form of modification.

ii. For nanocellulose blended with conventional proton conducting polymers (square data points), the conductivity is roughly proportional to the polymeric ionomer content, as highlighted by the light grey region. Blends containing less than $\sim 20$ wt $\%$ cellulose have conductivity close to that of the pure ionomer membrane, or in some cases even higher. As such, nanocellulose may be useful in low amounts as a reinforcing agent, without compromising the conductivity of conventional ionomers. The highest conductivity was recorded for the non-conventional ionomer PMOEP, which doesn't readily form membranes in its pure form. This is a promising result, hinting that new unexplored ionomer materials with high conductivity could be stabilized using cellulose as an additive.

iii. Chemical modification (triangular data points) especially via sulfonation is clearly an effective and highly promising method to increase the conductivity of cellulose membranes by up to three orders of magnitude, approaching values normally associated with conventional ionomer materials. However, sulfonation is also known to affect mechanical stability, and thus care must be taken that this does not translate to poor device durability. More 


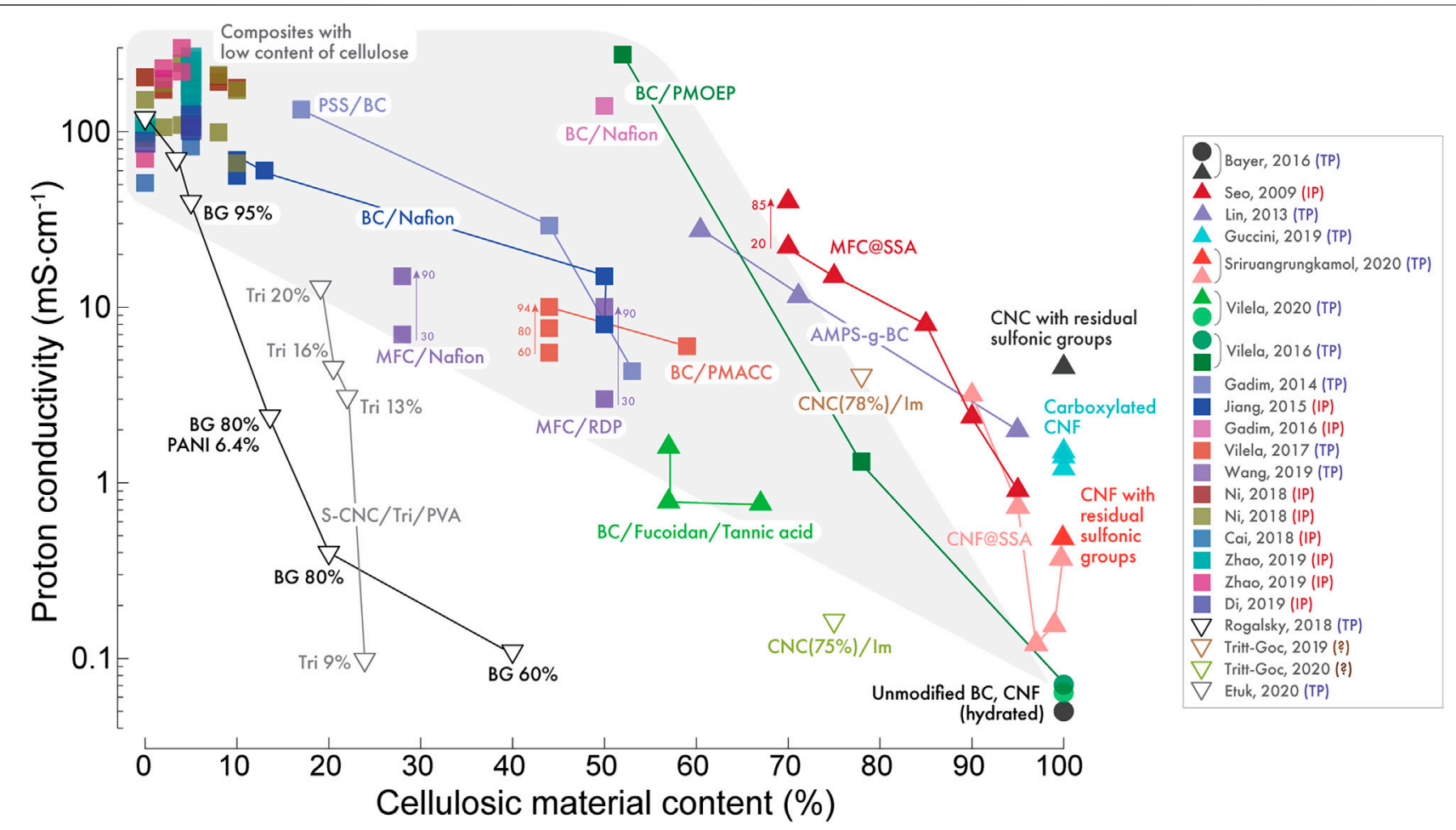

FIGURE 15 | Summary of the proton conductivity of different cellulose containing PEMs reported in the literature, showing the best reported conductivity as a function of the cellulose content in the membrane. Circular data points represent pure cellulose; square points polymer blends; triangular data points functionalized cellulose; and inverted triangles for mixtures with small molecules. Hollow data points were measured in anhydrous conditions. Arrows with numbers indicate the conductivity of same membrane measured at different temperatures $\left({ }^{\circ} \mathrm{C}\right)$. Initials following the references indicate if measurements were taken in plane (IP), through-plane (TP), or unreported (?).

studies should investigate the long term stability of cellulosebased membranes, and techniques such as crosslinking may be useful to avoid this this problem. In addition, not only sulfonation but carboxylation, phosphorylation etc. should also be investigated.

iv. Doping with small molecules (inverted triangles) such as imidazole has mainly been explored in anhydrous (hollow data points), high temperature conditions. As such the measured conductivities are relatively low. Again, the issue of durability will be important if this line of research is continued, since small molecules will evaporate during heating cycles, and leach out of the membrane with water generated at the cathode.

v. Studies reporting on the measurement of cellulosic membranes in anhydrous conditions tend to report very low values of proton conductivity. This highlights the importance of the presence water molecules in the conduction mechanisms of these materials. As such, for cellulose research should mainly be focused on the study of hydrated systems. However, to date there is very little research into the fundamental relationship between cellulose, water and proton conduction. As such, it would be of interest to determine factors such as the hydration number in future studies.

vi. Finally, when the proton conductivity is measured using inplane configuration, the measured values will inevitably be much higher than when measured using through-plane configurations, perhaps by orders of magnitude. Ideally, through-plane measurements should be conducted whenever possible, since in most electrochemical devices, hydrogen ions pass through the membrane bulk between the electrodes.

\section{Summary and Future Outlook}

Despite the high abundance, low cost, long history, and versatile surface chemistry of cellulosic materials, surprisingly few studies have investigated their potential use in proton exchange membranes. However, thanks to a handful of studies published in recent years, this field is gaining momentum. Here, we have reviewed the reports published so far which investigate the ionic conductivity of cellulose derivatives either in their native form, as blends with polymer ionomers or small molecules, and after undergoing chemical modification. Whilst systematic studies are still lacking, we believe that this summary will provide the clues for new advances. Pure unadulterated cellulosic materials were found to have proton conductivity too low to be realistically applied in electrochemical devices. Blending small amounts of nanocellulose with conventional ionomers improves the mechanical strength without compromising (or even slightly increasing in some cases) the proton conductivity. Chemical 
modification via sulfonation appears to be the most promising tactic for improving the proton conductivity of cellulosic materials, with values approaching those of state-of-the-art sulfonated fluoropolymer ionomer membranes. Overall, the proton conductivity of cellulosic materials is currently too low for real-world application in e.g. PEMFCs. However, with new materials advances and more systematic research, such applications may be within reach.

\section{AUTHOR CONTRIBUTIONS}

The manuscript was written through the contributions of all authors, and all authors approved the final version of the manuscript.

\section{REFERENCES}

Allen, F. I., Comolli, L. R., Kusoglu, A., Modestino, M. A., Minor, A. M., and Weber, A. Z. (2015). Morphology of hydrated as-cast Nafion revealed through cryo electron tomography. ACS Macro Lett. 4, 1-5. doi:10.1021/mz500606h

Ataide, J. A., De Carvalho, N. M., Rebelo, M. D. A., Chaud, M. V., Grotto, D., Gerenutti, M., et al. (2017). Bacterial nanocellulose loaded with bromelain: assessment of antimicrobial, antioxidant and physical-chemical properties. Sci. Rep. 7, 2-10. doi:10.1038/s41598-017-18271-4.

Barker, R. E., and Thomas, C. R. (1964a). Effects of moisture and high electric fields on conductivity in alkali-halide-doped cellulose acetate. J. Appl. Phys. 35, 3203-3215. doi:10.1063/1.1713200.

Barker, R. E., and Thomas, C. R. (1964b). Glass transition and ionic conductivity in cellulose acetate. J. Appl. Phys. 35, 87-94. doi:10.1063/1.1713104.

Bayer, T., Bishop, S. R., Nishihara, M., Sasaki, K., and Lyth, S. M. (2014). Characterization of a graphene oxide membrane fuel cell. J. Power Sources. 272, 239-247. doi:10.1016/j.jpowsour.2014.08.071.

Bayer, T., Cunning, B. V., Selyanchyn, R., Daio, T., Nishihara, M., Fujikawa, S., et al. (2016). Alkaline anion exchange membranes based on $\mathrm{KOH}$-treated multilayer graphene oxide J. Mem. Sci. 508, 51-61. doi:10.1016/j.memsci. 2016.02.017

Bayer, T., Cunning, B. V., Selyanchyn, R., Nishihara, M., Fujikawa, S., Sasaki, K., et al. (2016). High temperature proton conduction in nanocellulose membranes: paper fuel cells. Chem. Mater. 28, 4805-4814. doi:10.1021/acs. chemmater.6b01990

Bayer, T., Selyanchyn, R., Fujikawa, S., Sasaki, K., and Lyth, S. M. (2017). Spraypainted graphene oxide membrane fuel cells. J. Memb. Sci. 541, 347-357. doi:10. 1016/j.memsci.2017.07.012

Breitwieser, M., Bayer, T., Büchler, A., Zengerle, R., Lyth, S. M., and Thiele, S. (2017). A fully spray-coated fuel cell membrane electrode assembly using Aquivion ionomer with a graphene oxide/cerium oxide interlayer. J. Power Sources. 351, 145-150. doi:10.1016/j.jpowsour.2017.03.085

Cai, Z., Li, R., Xu, X., Sun, G., Zhuang, X., Liu, Y., et al. (2018). Embedding phosphoric acid-doped cellulose nanofibers into sulfonated poly (ether sulfone) for proton exchange membrane. Polymer (Guildf). 156, 179-185. doi:10.1016/j. polymer.2018.10.013.

Cao, Y.-C., Xu, C., Wu, X., Wang, X., Xing, L., and Scott, K. (2011). A poly (ethylene oxide)/graphene oxide electrolyte membrane for low temperature polymer fuel cells. J. Power Sources. 196, 8377-8382. doi:10.1016/j.jpowsour. 2011.06.074

Crofton, D. J., and Pethrick, R. A. (1981). Dielectric studies of proton migration and relaxation in wet cellulose and its derivatives. Polymer (Guildf). 22, 1048-1053. doi:10.1016/0032-3861(81)90290-1

Di, Y., and Yin, X. (2019). Reinforced proton conductivity through imidazoleloaded cellulose nanofibers for proton exchange membranes. Mater. Res. Express 6. doi:10.1088/2053-1591/ab4384

\section{ACKNOWLEDGMENTS}

This work was supported by the Japan Science and Technology Agency (JST) through the "Center of Innovation Science and Technology based Radical Innovation and Entrepreneurship Program" (COI Program, Grant No. JPMJCE1318). The World Premier International Research Center Initiative (WPI), is sponsored by the Japanese Ministry of Education, Culture, Sports, Science, and Technology (MEXT). O. Selyanchyn acknowledges the Kyushu University Platform of Inter/Transdisciplinary Energy Research Support Program for Doctoral Students. R. Selyanchyn acknowledges the Japan Society for Promotion of Science (JSPS) for a Grant-in-Aid for Early Career Scientists (no. JP19K15342).

Dias, O. A. T., Konar, S., Leão, A. L., Yang, W., Tjong, J., and Sain, M. (2020). Current state of applications of nanocellulose in flexible energy and electronic devices. Front. Chem. 8. doi:10.3389/fchem.2020.00420.

Dufresne, A. (2013). Nanocellulose: a new ageless bionanomaterial. Mater. Today. 16, 220-227. doi:10.1016/j.mattod.2013.06.004.

Eichhorn, S. J., Dufresne, A., Aranguren, M., Marcovich, N. E., Capadona, J. R., Rowan, S. J., et al. (2010). Review: current international research into cellulose nanofibres and nanocomposites. J. Mater. Sci. 45, 1-33. doi:10.1007/s10853009-3874-0

Etuk, S. S., Lawan, I., Zhou, W., Jiang, Y., Zhang, Q., Wei, X., et al. (2020). Synthesis and characterization of triazole based sulfonated nanocrystalline cellulose proton conductor. Cellulose 27, 3197-3209. doi:10.1007/s10570-020-02981-6.

Evans, B. R., O’Neill, H. M., Malyvanh, V. P., Lee, I., and Woodward, J. (2003). Palladium-bacterial cellulose membranes for fuel cells. Biosens. Bioelectron. 18, 917-923. doi:10.1016/S0956-5663(02)00212-9

Farzin, S., Johnson, T. J., Chatterjee, S., Zamani, E., and Dishari, S. K. (2020). Ionomers from kraft lignin for renewable energy applications. Front. Chem. 8. doi:10.3389/fchem.2020.00690

Feng, S., Kondo, S., Kaseyama, T., Nakazawa, T., Kikuchi, T., Selyanchyn, R., et al. (2018). Development of polymer-polymer type charge-transfer blend membranes for fuel cell application. J. Membr. Sci. 548, 223-231. doi:10. 1016/j.memsci.2017.11.025

Gadim, T. D. O., Figueiredo, A. G. P. R., Rosero-Navarro, N. C., Vilela, C., Gamelas, J. A. F., Barros-Timmons, A., et al. (2014). Nanostructured bacterial cellulosepoly(4-styrene sulfonic acid) composite membranes with high storage modulus and protonic conductivity. ACS Appl. Mater. Interfaces. 6, 7864-7875. doi:10. 1021/am501191t

Gadim, T. D. O., Loureiro, F. J. A., Vilela, C., Rosero-Navarro, N., Silvestre, A. J. D., Freire, C. S. R., et al. (2017). Protonic conductivity and fuel cell tests of nanocomposite membranes based on bacterial cellulose. Electrochim. Acta. 233, 52-61. doi:10.1016/j.electacta.2017.02.145.

Gadim, T. D. O., Vilela, C., Loureiro, F. J. A., Silvestre, A. J. D., Freire, C. S. R., and Figueiredo, F. M. L. (2016). Nafion ${ }^{\circledR}$ and nanocellulose: a partnership for greener polymer electrolyte membranes. Ind. Crops Prod. 93, 212-218. doi:10. 1016/j.indcrop.2016.01.028

Garcia de Rodriguez, N. L., Thielemans, W., and Dufresne, A. (2006). Sisal cellulose whiskers reinforced polyvinyl acetate nanocomposites. Cellulose 13, 261-270. doi:10.1007/s10570-005-9039-7.

Gardner, C. L., and Anantaraman, A. V. (1998). Studies on ion-exchange membranes. II. Measurement of the anisotropic conductance of Nafion ${ }^{\circledR}$. J. Electroanal. Chem. 449, 209-214. doi:10.1016/S0022-0728(97)00408-7.

Gibson, L. J. (2012). The hierarchical structure and mechanics of plant materials. J. R. Soc. Interface. 9, 2749-2766. doi:10.1098/rsif.2012.0341.

Guccini, V., Carlson, A., Yu, S., Lindbergh, G., Lindström, R. W., Salazar-Alvarez, G., et al. (2019). Highly proton conductive membranes based on carboxylated cellulose nanofibres and their performance in proton exchange membrane fuel cells. J. Mater. Chem. A 7, 25032-25039. doi:10.1039/c9ta04898g. 
Guilminot, E., Fischer, F., Chatenet, M., Rigacci, A., Berthon-Fabry, S., Achard, P., et al. (2007). Use of cellulose-based carbon aerogels as catalyst support for PEM fuel cell electrodes: electrochemical characterization. J. Power Sources. 166, 104-111. doi:10.1016/j.jpowsour.2006.12.084.

Habibi, Y., Lucia, L. A., and Rojas, O. J. (2010). Cellulose nanocrystals: chemistry, selfassembly, and applications, Chem. Rev. 110, 3479-3500. doi:10.1021/cr900339w

Heinze, T. (2016). Cellulose: structure and properties. Adv. Polym. Sci. 271, 1-52. doi:10.1007/12_2015_319

Heitner, C., Dimmel, D., and Schmidt, J. (2010). Lignin and lignans: Advances in chemistry Boca Raton: CRC Press.

Hou, S., Su, H., Zou, H., Dang, D., Song, H., Li, X., et al. (2015). Enhanced lowhumidity performance in a proton exchange membrane fuel cell by the insertion of microcrystalline cellulose between the gas diffusion layer and the anode catalyst layer. Int. J. Hydrogen Energy. 40, 15613-15621. doi:10. 1016/j.ijhydene.2015.09.084.

Irmak, S., (2018). "Challenges of biomass utilization for biofuels" in biomass for bioenergy - recent trends and future challenges, ed. Abd El-Fatah Abomohra. InTech Publisher, Rijeka, Croatia, ISBN 978-1-78923-988-1. doi:10.5772/ intechopen.83752.

Jankowska, I., Pankiewicz, R., Pogorzelec-Glaser, K., Ławniczak, P., Łapiński, A., and Tritt-Goc, J. (2018). Comparison of structural, thermal and proton conductivity properties of micro- and nanocelluloses. Carbohydr. Polym. 200, 536-542. doi:10.1016/j.carbpol.2018.08.033.

Jiang, G.-P., Zhang, J., Qiao, J.-L., Jiang, Y.-M., Zarrin, H., Chen, Z., et al. (2015). Bacterial nanocellulose/Nafion composite membranes for low temperature polymer electrolyte fuel cells. J. Power Sources. 273, 697-706. doi:10.1016/j. jpowsour.2014.09.145

Jiang, G., Qiao, J., and Hong, F. (2012). Application of phosphoric acid and phytic acid-doped bacterial cellulose as novel proton-conducting membranes to PEMFC. Int. J. Hydrogen Energy. 37, 9182-9192. doi:10.1016/j.ijhydene.2012.02.195.

Jonoobi, M., Oladi, R., Davoudpour, Y., Oksman, K., Dufresne, A., Hamzeh, Y., et al. (2015). Different preparation methods and properties of nanostructured cellulose from various natural resources and residues: a review. Cellulose 22, 935-969. doi:10.1007/s10570-015-0551-0.

Klemm, D., Heublein, B., Fink, H. P., and Bohn, A. (2005). Cellulose: fascinating biopolymer and sustainable raw material. Angew Chemie - Int Ed. 44, 3358-3393. doi:10.1002/anie.200460587

Kreuer, K. D. (2001). On the development of proton conducting polymer membranes for hydrogen and methanol fuel cells. J. Membr. Sci. 185, 29-39. doi:10.1016/S0376-7388(00)00632-3

Kreuer, K. D., Paddison, S. J., Spohr, E., and Schuster, M. (2004). Transport in proton conductors for fuel-cell applications: simulations, elementary reactions, and phenomenology. Chem. Rev. 104, 4637-4678. doi:10.1021/cr020715f.

Lin, C. W., Liang, S. S., Chen, S. W., and Lai, J. T. (2013). Sorption and transport properties of 2-acrylamido-2-methyl-1- propanesulfonic acid-grafted bacterial cellulose membranes for fuel cell application. J. Power Sources. 232, 297-305. doi:10.1016/j.jpowsour.2013.01.047.

Ma, J., and Sahai, Y. (2013). Chitosan biopolymer for fuel cell applications. Carbohydr. Polym. 92, 955-975. doi:10.1016/j.carbpol.2012.10.015

Mauritz, K. A., and Moore, R. B., (2004). State of understanding of nafion. Chem. Rev. 104, 4535-4585. doi:10.1021/cr0207123

Mohanty, A. K., Vivekanandhan, S., Pin, J.-M., and Misra, M. (2018). Composites from renewable and sustainable resources: challenges and innovations. Science 362, 536-542. doi:10.1126/science.aat9072.

Murphy, E. J. (1960a). The temperature dependence of the conductivity of dry cellulose. J. Phys. Chem. Solids 15, 66-71. doi:10.1016/0022-3697(60)90101-3.

Murphy, E. J. (1960b). The dependence of the conductivity of cellulose, silk and wool on their water content. J. Phys. Chem. Solids 16, 115-122. doi:10.1016/ 0022-3697(60)90081-0.

Ni, C., Wang, H., Zhao, Q., Liu, B., Sun, Z., Zhang, M., et al. (2018). Crosslinking effect in nanocrystalline cellulose reinforced sulfonated poly(aryl ether ketone) proton exchange membranes. Solid State Ionics. 323, 5-15. doi:10.1016/j.ssi.2018.05.004.

Ni, C., Wei, Y., Zhao, Q., Liu, B., Sun, Z., Gu, Y., et al. (2018). Novel proton exchange membranes based on structure-optimized poly(ether ether ketone ketone)s and nanocrystalline cellulose. Appl. Surf. Sci. 434, 163-175. doi:10. 1016/j.apsusc.2017.09.094.

Ohma, A., Shinohara, K., Iiyama, A., Yoshida, T., and Daimaru, A. (2011). Membrane and catalyst performance targets for automotive fuel cells by
FCCJ membrane, catalyst, MEA WG. ECS Trans. 41, 775-784. doi:10.1149/ 1.3635611 .

Peckham, T. J., and Holdcroft, S. (2010). Structure-morphology-property relationships of non-perfluorinated proton-conducting membranes. Adv. Mater. 22, 4667-4690. doi:10.1002/adma.201001164.

Pelissari, F. M., Sobral, P. J. D. A., and Menegalli, F. C. (2014). Isolation and characterization of cellulose nanofibers from banana peels. Cellulose 21, 417-432. doi:10.1007/s10570-013-0138-6.

Rogalsky, S., Bardeau, J. F., Makhno, S., Babkina, N., Tarasyuk, O., Cherniavska, T., et al. (2018). New proton conducting membrane based on bacterial cellulose/ polyaniline nanocomposite film impregnated with guanidinium-based ionic liquid. Polymer (Guildf). 142, 183-195. doi:10.1016/j.polymer.2018.03.032.

Seo, J. A., Kim, J. C., Koh, J. K., Ahn, S. H., and Kim, J. H. (2009). Preparation and characterization of crosslinked cellulose/sulfosuccinic acid membranes as proton conducting electrolytes. Ionics 15, 555-560. doi:10.1007/s11581-0090314-8

Sjöström, E. (1993). Wood chemistry fundamentals and applications. 2nd edition. San Diego, CA: Academic Press, Inc.

Smolarkiewicz, I., Rachocki, A., Pogorzelec-glaser, K., and Pankiewicz, R. (2014). Proton-conducting microcrystalline cellulose doped with imidazole. Thermal and electrical properties. Electrochim. Acta. 155, 38-44. doi:10.1016/j.electacta. 2014.11.205.

Sriruangrungkamol, A., and Chonkaew, W. (2020). Modification of nanocellulose membrane by impregnation method with sulfosuccinic acid for direct methanol fuel cell applications. Polym. Bull. doi:10.1007/s00289-020-03289-y.

Takahashi, M., and Takenaka, H. (1983). Dc electrical conductivity of cellulose. Polym. J. 15, 625-629. doi:10.1295/polymj.15.625.

Thomas, B., Raj, M. C., Athira, B. K., Rubiyah, H. M., Joy, J., Moores, A., et al. (2018). Nanocellulose, a versatile green Platform: from biosources to materials and their applications. Chem. Rev. 118, 11575-11625. doi:10.1021/acs.chemrev. $7 \mathrm{~b} 00627$

Trache, D., Tarchoun, A. F., Derradji, M., Hamidon, T. S., Masruchin, N., Brosse, N., et al. (2020). Nanocellulose: from fundamentals to advanced applications. Front. Chem. 8:392. doi:10.3389/fchem.2020.00392.

Tritt-Goc, J., Jankowska, I., Pogorzelec-Glaser, K., Pankiewicz, R., and Ławniczak, P. (2018). Imidazole-doped nanocrystalline cellulose solid proton conductor: synthesis, thermal properties, and conductivity. Cellulose, 25, 281-291. doi:10. 1007/s10570-017-1555-8

Tritt-Goc, J., Lindner, Bielejewski, M., Markiewicz, E., and Pankiewicz, R. (2019). Proton conductivity and proton dynamics in nanocrystalline cellulose functionalized with imidazole. Carbohydr. Polym. 225, 115196. doi:10.1016/j. carbpol.2019.115196.

Tritt-Goc, J., Lindner, Bielejewski, M., Markiewicz, E., and Pankiewicz, R. (2020). Synthesis, thermal properties, conductivity and lifetime of proton conductors based on nanocrystalline cellulose surface-functionalized with triazole and imidazole. Int. J. Hydrogen Energy. 45, 13365-13375. doi:10.1016/j.ijhydene. 2020.03.071.

Turbak, A. F., Snyder, F. W., and Sandberg, K. R. (1983). Microfibrillated cellulose, a new cellulose product: properties, uses, and commercial potential. Applied Polymer Symposia. 37, 815-827.

Usov, I., Nyström, G., Adamcik, J., Handschin, S., Schütz, C., Fall, A., et al. (2015). Understanding nanocellulose chirality and structure-properties relationship at the single fibril level. Nat. Commun. 6, 7564. doi:10.1038/ncomms8564

Vilela, C., Gadim, T. D. O., Silvestre, A. J. D., Freire, C. S. R., and Figueiredo, F. M. L. (2016). Nanocellulose/poly(methacryloyloxyethyl phosphate) composites as proton separator materials. Cellulose 23, 3677-3689. doi:10.1007/s10570-0161050-7

Vilela, C., Morais, J. D., Silva, A. C. Q., Muñoz-Gil, D., Figueiredo, F. M. L., Silvestre, A. J. D., et al. (2020). Flexible nanocellulose/lignosulfonates ionconducting separators for polymer electrolyte fuel cells. Nanomaterials 10, 1713. doi:10.3390/nano10091713.

Vilela, C., Silva, A. C. Q., Domingues, E. M., Gonçalves, G., Martins, M. A., Figueiredo, F. M. L., et al. (2020). Conductive polysaccharides-based proton-exchange membranes for fuel cell applications: the case of bacterial cellulose and fucoidan. Carbohydr. Polym. 230, 115604. doi:10.1016/j.carbpol.2019.115604.

Vilela, C., Silvestre, A. J. D., Figueiredo, F. M. L., and Freire, C. S. R. (2019). Nanocellulose-based materials as components of polymer electrolyte fuel cells. J. Mater. Chem. 7, 20045-20074. doi:10.1039/c9ta07466j. 
Wang, L., Zuo, X., Raut, A., Isseroff, R., Xue, Y., Zhou, Y., et al. (2019). Operation of proton exchange membrane (PEM) fuel cells using natural cellulose fiber membranes. Sustain. Energy Fuels. 3, 2725-2732. doi:10.1039/ c9se00381a

Xu, C., Cao, Y., Kumar, R., Wu, X., Wang, X., and Scott, K. (2011). A polybenzimidazole/sulfonated graphite oxide composite membrane for high temperature polymer electrolyte membrane fuel cells J. Mater. Chem., 21, 1359-11364. doi:10.1039/cljm11159k.

Yamasaki, S., Sakuma, W., Yasui, H., Daicho, K., Saito, T., Fujisawa, S., et al. (2019). Nanocellulose xerogels with high porosities and large specific surface areas. Front. Chem. 7, 1-8. doi:10.3389/fchem.2019.00316.

Yang, J., Sun, D., Li, J., Yang, X., Yu, J., Hao, Q., et al. (2009). In situ deposition of platinum nanoparticles on bacterial cellulose membranes and evaluation of PEM fuel cell performance. Electrochim. Acta. 54, 6300-6305. doi:10.1016/j. electacta.2009.05.073.
Zhao, G., Xu, X., Di, Y., Wang, H., Cheng, B., Shi, L., et al. (2019). Amino acid clusters supported by cellulose nanofibers for proton exchange membranes. J. Power Sources. 438. doi:10.1016/j.jpowsour.2019.227035.

Conflict of Interest: The authors declare that the research was conducted in the absence of any commercial or financial relationships that could be construed as a potential conflict of interest.

Copyright $\odot 2020$ Selyanchyn, Selyanchyn and Lyth. This is an open-access article distributed under the terms of the Creative Commons Attribution License (CC BY). The use, distribution or reproduction in other forums is permitted, provided the original author(s) and the copyright owner(s) are credited and that the original publication in this journal is cited, in accordance with accepted academic practice. No use, distribution or reproduction is permitted which does not comply with these terms. 